\title{
Solar type II and type IV radio bursts observed during 1998-2000 with the ARTEMIS-IV radiospectrograph $\star$
}

\author{
C. Caroubalos ${ }^{1}$, A. Hillaris ${ }^{2}$, C. Bouratzis ${ }^{2}$, C. E. Alissandrakis ${ }^{3}$, P. Preka-Papadema ${ }^{2}$, J. Polygiannakis ${ }^{2}$, \\ P. Tsitsipis ${ }^{4}$, A. Kontogeorgos ${ }^{4}$, X. Moussas ${ }^{2}$, J.-L. Bougeret ${ }^{5}$, G. Dumas ${ }^{5}$, and C. Perche ${ }^{5}$ \\ ${ }^{1}$ Department of Informatics, University of Athens, 15783 Athens, Greece \\ 2 Section of Astrophysics, Astronomy and Mechanics, Department of Physics, University of Athens, \\ 15784 Panepistimiopolis Zografos, Athens, Greece \\ 3 Section of Astro-Geophysics, Department of Physics, University of Ioannina, 45110 Ioannina, Greece \\ 4 Department of Electronics, Technological Education Institute of Lamia, Lamia, Greece \\ 5 Observatoire de Paris, Departement de Recherche Spatiale, CNRS UA 264, 92195 Meudon Cedex, France
}

Received 2 April 2002 / Accepted 29 August 2003

\begin{abstract}
A catalogue of the type II and type IV solar radio bursts in the 110-687 MHz range, observed with the radio spectrograph ARTEMIS-IV operated by the University of Athens at Thermopylae, Greece from 1998-2000 is presented. These observations are compared with the LASCO archives of Coronal Mass Ejections and the Solar Geophysical Reports of solar flares (H $\alpha$ \& SXR) and examined for possible associations. The main results are:

- $68 \%$ of the catalogue events were associated with CMEs.

- $67 \%$ of the type II events were associated with CMEs, in accordance with previous results. This percentage rises to $79 \%$ in the case of composite type II/IV events.

- $77 \%$ of the type IV continua were associated with CMEs, which is higher that the CME-type II association probability.

- The type II associated CMEs had an average velocity of $(835 \pm 380) \mathrm{km} \mathrm{s}^{-1}$, while the CMEs not associated with type IIs had an average velocity of $(500 \pm 150) \mathrm{km} \mathrm{s}^{-1}$.

- All events, but one, were well associated with $\mathrm{H} \alpha$ and/or SXR flares.

- Most of the CME launch times precede by 5-60 min (30 min on average) the associated SXR flare peak; an important fraction $(72 \%)$ precede the flare onset as well.
\end{abstract}

Key words. astronomical data bases: miscellaneous - catalogs - Sun: activity - Sun: corona - Sun: flares Sun: radio radiation

\section{Introduction}

Type II bursts represent the passage of a MHD shock wave through the tenuous plasma of the solar corona (Wild \& Smerd 1972); their radio emission is due either to energetic electrons accelerated at the shock front or plasma turbulence excited by the shock. Although they are associated with eruptive phenomena and are identified either with a flare blast wave (Vrsnak et al. 2001) or with a CME forward shock (Kahler et al. 1984; Maia et al. 2000; Aurass 1997) or with a shock driven by the flanks of a CME (Classen \& Aurass 2002), their exact origin has not been unambiguously determined (Klassen et al. 1999); furthermore Pearson et al. (1989)

Send offprint requests to: $\mathrm{X}$. Moussas,

e-mail: xmoussas@cc.uoa.gr

* Appendix A is only available in electronic form at http://www . edpsciences.org question the type II association with the most energetic and impulsive flares, demonstrating an almost equal probability of type II association with smaller flares as well.

Recent observations place the origin in rapidly expanding or disrupting magnetic structures in the outskirts of flaring active regions, thus stressing the association of metric and decametric type II bursts with flares rather than CMEs (Klein et al. 1999); Classen \& Aurass (2002) on the other hand, establish an almost equal probability for a type II to be driven by a flare blast, the front of a CME or its flank; they categorise accordingly type II as class 1, class 2 and class 3.

The dynamic spectra of type II events appear as slowly drifting bands, from high to low frequencies; they often exhibit a characteristic fundamental-harmonic structure (Maxwell \& Thompson 1962), as well as significant fine structure (Mann et al. 1996; Slottje 1981) dubbed herringbone or backbone. 
More often than not, the appearance of type II radio bursts is preceded by groups of bursts of the type III family. On the dynamic spectra the onset of the type III activity seems be in the same spectral range as the backward extrapolated type II lanes; Wild et al. (1963) named this type of event compound and concluded that both the type III and the type II bursts originated from a common source. Recently, Klassen et al. (1999) reported two more spectral features physically related to the type II exciter: the type II precursor consists of fast drift bursts or pulsations with a restricted bandwidth near the spectral range of the backward extrapolated type II lanes; the arc consists of a series of narrow-band bursts immediately preceding the type II onset; it has an inverted U-shaped envelope, hence its name.

The continua observed during periods of activity, on the other hand, represent the radiation of energetic electrons trapped within magnetic structures and plasmoids and they appear under the name type IV bursts (Kundu et al. 2001). The stationary type IV bursts (IV $\mathrm{mB}$ ) emanate from magnetic structures usually located above active regions (Robinson 1985); they often present significant fine structure (Slottje 1981). The moving type IV bursts (Boischot 1957) are emitted from sources of meter wave continuum which are believed to move outwards at velocities of the order of $100-1000 \mathrm{~km} \mathrm{~s}^{-1}$; their spectrum is often featureless and sometimes last more than $10 \mathrm{~min}$. Some of them appear following type II bursts and are possibly caused by energetic electrons produced in the wake of the type II shock. Others may originate from energetic electron populations trapped in expanding magnetic arches or plasmoids, i.e. blobs of dense plasma containing their own magnetic field (cf. Wild \& Smerd 1972; Stewart 1985 and references therein). A number of moving type IV (IV $\mathrm{mA}$ ) bursts are believed to originate within the densest substructures of CMEs (Aurass 1997; Aurass et al. 1999); the work by Klein \& Mouradian (2002), Bastian et al. (2001) provides more evidence which corroborates this point of view, associating the type IV source with the erupting prominences within the CMEs.

Coronal Mass Ejections (CMEs) are solar transients characterised by the expulsion of solar plasma and frozen in magnetic field from the corona to the interplanetary space; their driving mechanism is probably magnetic (Amari et al. 2000; Vourlidas et al. 2000; Wu et al. 2001). The association of CMEs with other types of solar activity has been studied meticulously (cf. for example Hildner et al. 1976 on the CME-Sunspot Number association, Webb \& Hundhausen 1987 and Munro et al. 1979 on the association with Eruptive Prominences and long duration events (LDEs) (also Gilbert et al. 2000; Kahler et al. 1989), flares (cf. also Svestka 2001), radio bursts (cf. also Maia et al. 2000)), flares and filament eruptions (Guiping Zhou et al. 2003), solar energetic electron events and coronal shocks (Klassen et al. 2002), but the results are not conclusive. Therefore both the CME origin and their association with active solar features are open research issues since our understanding of both is still uncertain. Catalogues of recorded CMEs, some including associated phenomena, have already been compiled and published (cf. for example Yashiro et al. 2001; Gil Moreno et al. 1998).
In this article we present a catalogue of all the type II and IV solar radio bursts observed during 1998-2000 by the ARTEMIS-IV Solar Radio spectrograph, including associated CMEs and flares from the LASCO archives and the Solar Geophysical Data (SGD) respectively. Throughout this report, type II bursts followed by type IV continua are referred to as type II/IV events. In Sect. 2 we describe our instrumentation and the observations used in the compilation of our catalogue; in Sect. 3 we present our results based on this catalogue. Discussion of results and conclusions appear in Sect. 4, while the catalogue is given in the appendix.

\section{Observations}

\subsection{Instrumentation}

Our radio data were obtained with the ARTEMIS-IV solar radio spectrograph (Caroubalos et al. 2001a), operating at Thermopylae, Greece ( $\left.38^{\circ} 49^{\prime} \mathrm{N}, 22^{\circ} 41^{\prime} \mathrm{E}\right)$. The daily observations cover the time interval 05:30-15:00 UT. The instrument covers the frequency range of 110 to $687 \mathrm{MHz}$, using two receivers operating in parallel. The Global Spectral Analyser (ASG), a sweep frequency receiver and the AcoustoOptic Spectrograph (SAO), a multichannel acousto-optical receiver. The sweep frequency analyser (ASG) covers the full frequency band with a time resolution of 10 samples/s. The high sensitivity multi-channel acousto-optical analyser covers the 265-450 MHz range, with high frequency and time resolution (100 samples/s); its recordings are used, mostly, for the study of fine structures (cf. for example Caroubalos et al. 2001b).

\subsection{Event List}

In assembling the catalogue we included all the type II, IV and II/IV meter-wavelength events recorded by ARTEMIS-IV ASG during 1998-2000; during this three-year period the instrument was out of operation for technical reasons for about 12 months (see table in the appendix for the exact dates), thus the catalogue covers about twenty four months of observations. The dynamic spectra shown here are uncalibrated, but the minimum value has been subtracted from each channel. The SAO dynamic spectra in differential form were examined for type IV fine structure classification, as appropriate, when the recorded event, or part of it, was within the $265-450 \mathrm{MHz}$ range. We note that in the fine structure detection and classification we use differential spectra, which suppress the underlying continuum, enhancing the structures with shorter time scales (examples of dynamic spectra appear in Figs. 1 to 5).

Since a number of events exceeded the spectral range of ASG, we supplemented the information in our list with recordings and spectra from the Izmiran Radio spectrograph ${ }^{1}$, the Nançay Decametric Array ${ }^{2}$ and AIP (Potsdam) which were available on the Internet; these were used in the classification of recorded type II bursts as fundamental or harmonic, or for the detection of type II bursts originating outside the

\footnotetext{
${ }^{1}$ http://www.helios.izmiran.rssi.ru/lars/Archives

2 http://www.obs-nancay.fr/html-an/quicklook.php
} 


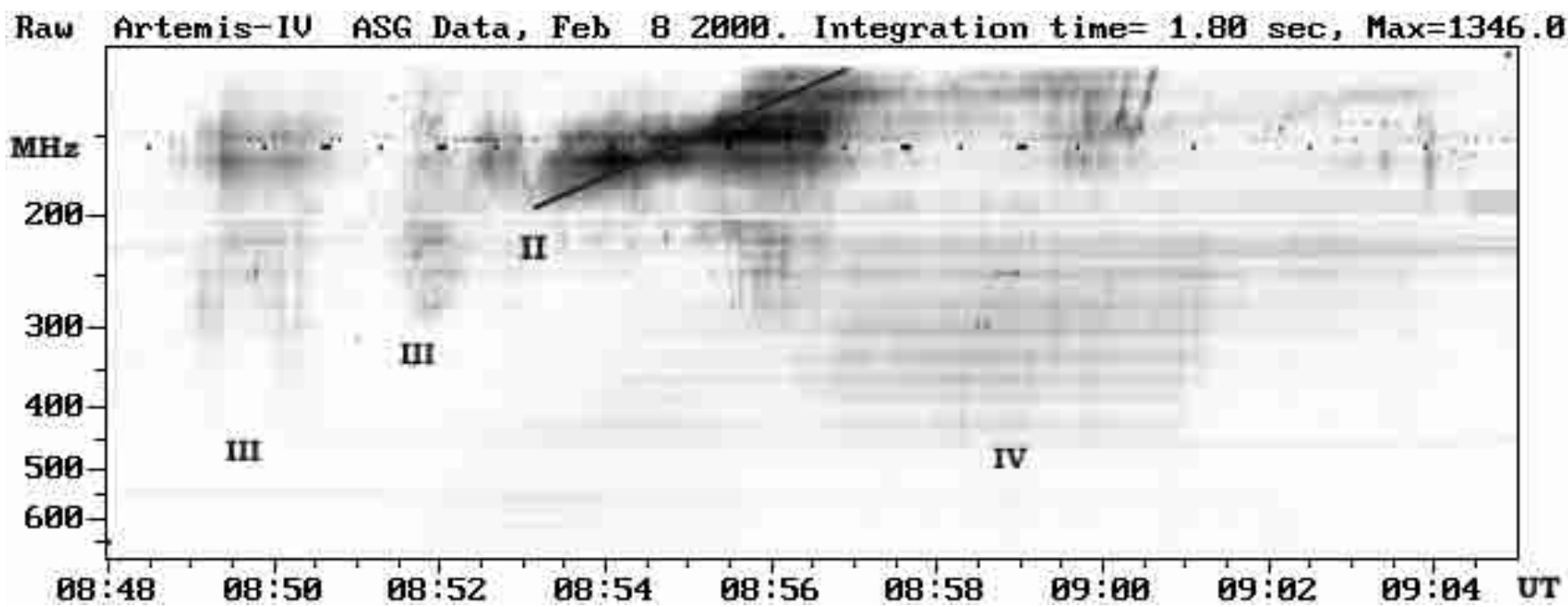

Raw Artemis-IU ASG Data, Feb 8 2080. Integration time $=1.80$ sec, Max=113?.0

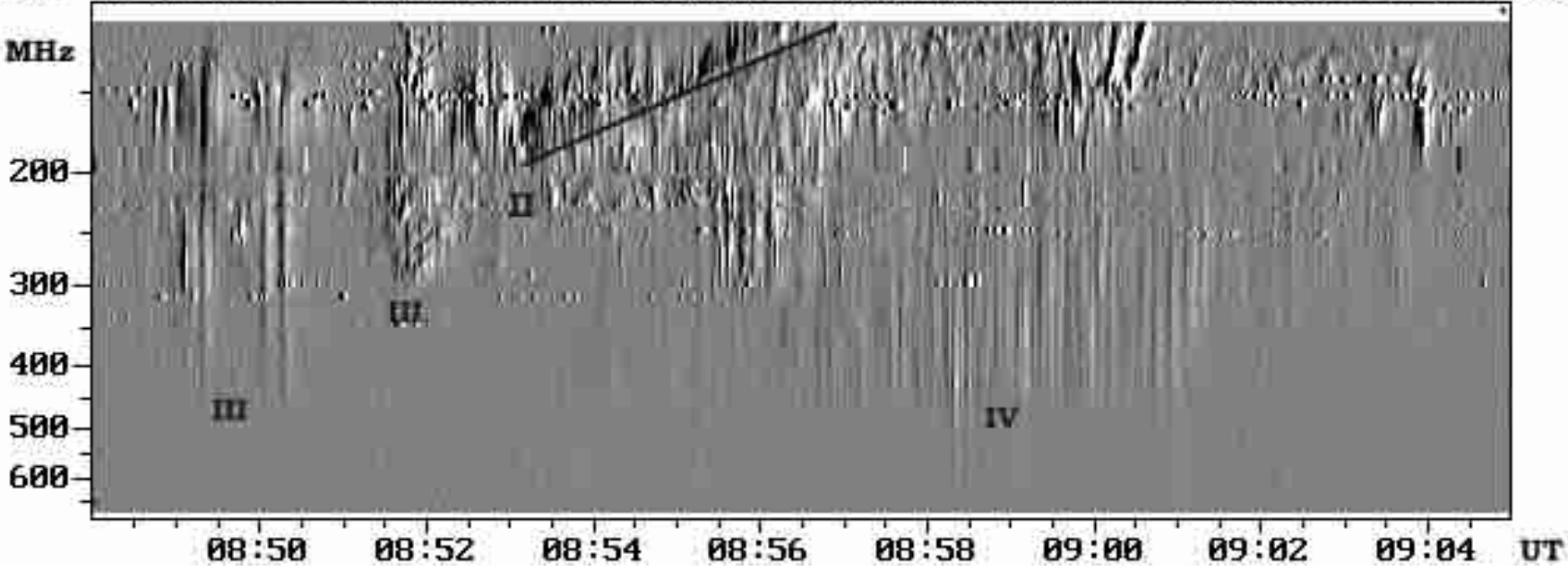

Fig. 1. ASG dynamic spectrum of the 2000 February 8 type II/IV event (\#23 in our catalog), preceded by a type III group with time resolution $1.0 \mathrm{~s}$. The bursts of different types have been annotated on image. Upper panel: intensity spectrum, Lower panel: differential spectrum (time derivative of intensity).

ARTEMIS-IV spectral range, yet accompanying continua of the ARTEMIS-IV catalogue. In Fig. 3 we present an example of an extended dynamic spectrum in the $687 \mathrm{MHz}-1 \mathrm{KHz}$ range, using combined spectral data from ARTEMIS-IV, the Nançay Decametric Array and the WIND/WAVES ${ }^{3}$ receivers (for a similar composite spectrum cf. Bougeret et al. 1998).

Most of the recorded type II bursts were in the first harmonic, as confirmed by the corresponding dynamic spectra of Izmiran and the $40-800 \mathrm{MHz}$ sweep spectrometer of the (AIP) Astrophysical Institute of Potsdam (Mann et al. 1992). The type II shock velocities $V_{\text {drift }}$ were estimated from the observed frequency drift rate using the Newkirk (Newkirk 1961, $1967)$ density $\left(N_{\mathrm{e}}\right.$, in $\left.\mathrm{cm}^{-3}\right)$ vs. height $\left(R\right.$, in $\left.R_{\odot}\right)$ coronal model:

$N_{\mathrm{e}}=8.3 \times 10^{4} \times 10^{4.32 / R}=8.3 \times 10^{4} \exp \left(\frac{9.947}{R}\right)$

and the equation (Tlamicha $\&$ Karlicky 1976):

$\frac{1}{f} \frac{\mathrm{d} f}{\mathrm{~d} t}=-V_{\mathrm{drift}} \frac{\left[\ln \left(0.037 f^{2}\right)\right]^{2}}{19.9}$

${ }^{3}$ http://lep694.gsfc.nasa.gov/waves/waves.html where $f$ is the frequency in $\mathrm{MHz}, V_{\text {drift }}$ is in $R_{\odot} / \mathrm{s}$ (Solar radii per second) and we have assumed radial propagation of the MHD shock and emission at the first harmonic of the local Langmuir frequency. Under the same assumption (radial propagation, Newkirk Corona, radiation at the first harmonic) we estimated by extrapolation the type II launch time, using its velocity and the height corresponding to its appearance on our recordings.

Then the LASCO coronagraph (Brueckner et al. 1995) event list was examined. The CME velocities and start times were estimated from the LASCO movies using the linear regression by Yashiro \& Michalek (Yashiro et al. 2001) and are available in the LASCO event list ${ }^{4}$. Following Classen \& Aurass (2002), we have adopted an error of $100 \mathrm{~km} \mathrm{~s}^{-1}$ in the CME velocity estimate which seems to cover both projection and acceleration or deceleration effects.

Lastly, the NOAA Solar Geophysical Data catalogues ${ }^{5}$ of GOES SXR and $\mathrm{H} \alpha$ flares were examined for possible

\footnotetext{
${ }^{4}$ http://cdaw.gsfc.nasa.gov/CME_list

5 http//www.sel.noaa.gov/ftpmenu/indices
} 
Raw Artemis-IU SAO Data, Feb 8 2000. Integration time $=1.00$ sec, Max $=1113.0$

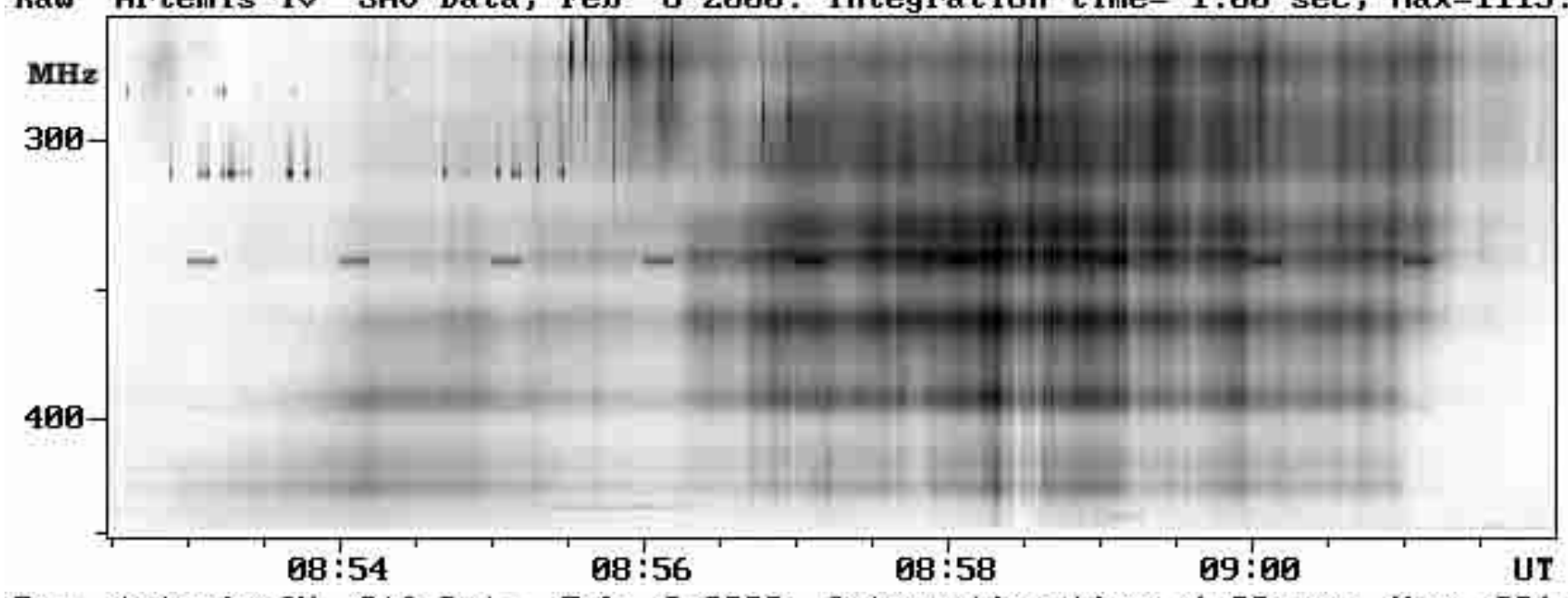

Raw Artemis-1U SAO Data, Feb 8 2000. Integration time $=1.00$ sec, Max $=881.0$

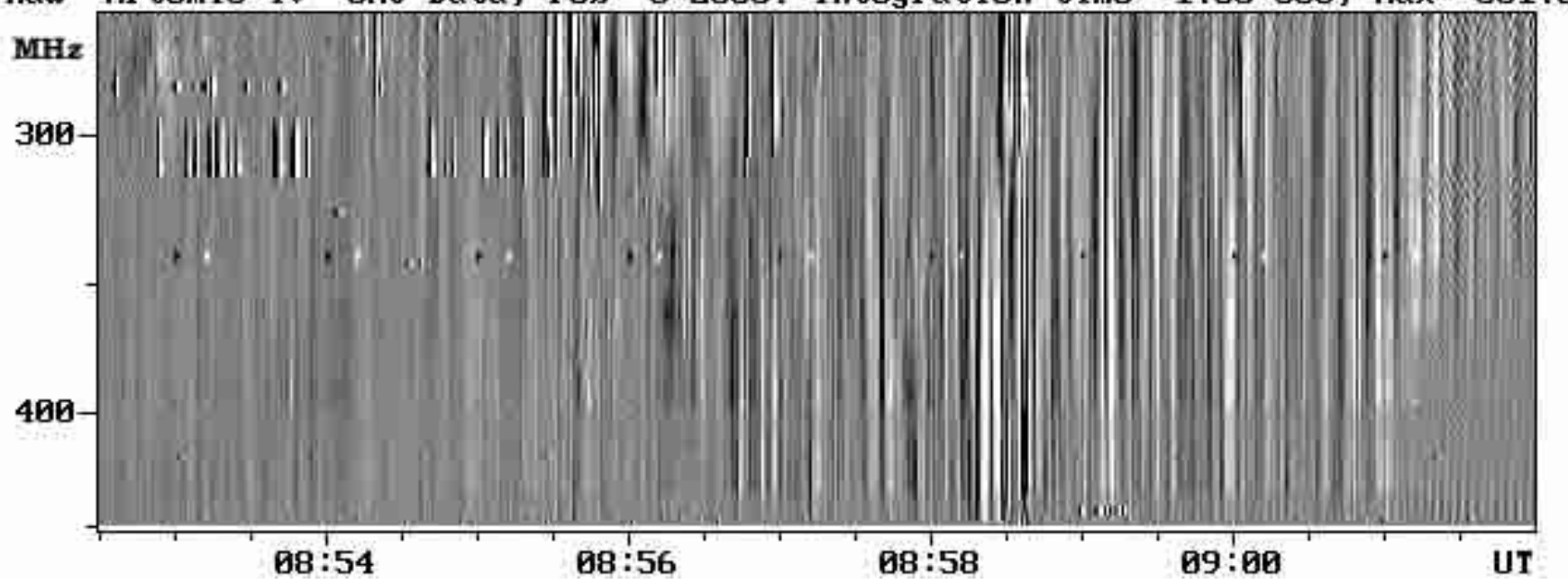

Fig. 2. SAO dynamic spectrum of the type IV burst of the 2000 February 8 complex event shown in Fig. 1. Upper panel: intensity spectrum, Lower panel: differential spectrum, which enhances the fine structure (pulsating) of the type IV continuum.

associations. The $\mathrm{H} \alpha$ flares were, at times, reported by more than one observatory. In those cases we chose the observation with the largest duration.

As regards the compilation of the type II, IV and II/IV ARTEMIS-IV 1998-2000 catalogue we adopted spatial and temporal criteria for the selection of the associated CMEs and flares (SXR and $\mathrm{H} \alpha$ ) as follows:

- For the metric radio burst-flare association: for the temporal association we adopted different criteria for the type IV continuum and the type II burst. For the former we required the overlap, at least in part, of the total duration of the flare with the total duration of the radio emission. For the latter we used the type II launch time with a twenty minute interval before and after it; a positive association was established if it overlapped with the flare duration. For the spatial criterion we used positional data (available for most of our events) from the Nançay Radioheliograph (Kedraon \& Delouis 1997) images and movies ${ }^{6}$; we examined coincidence with flares using their position recorded in the NOAA lists. If both criteria were satisfied we classified the association as excellent; otherwise, if the temporal criterion was violated slightly or we could not establish a spatial association due to lack of positional data, the association was characterised good. In the case of excellent association we indicate in our list the NOAA region from which the radio burst originates.

- For the CME association: from the time-height diagrams in the CME lists we defined a time window of $60 \mathrm{~min}$ between the CME takeoff time and the peak of the accompanying flare; this is a variant of the criterion used by Vrsnak et al. 2001 (a 60 min window from takeoff to the onset of the flare); we preferred to use the flare peak rather than the onset, since the former is more easily identifiable. To establish spatial association, we required that the flare and the CME originated within the same quadrant, otherwise we rejected the association; for this we compared the flare position with the CME central position angle and angular width. The spatial criterion, obviously, cannot be applied in the case of halo CMEs.

\footnotetext{
${ }^{6}$ BASS2000 French Solar Data Base: http//mesola.obspm. fr
} 


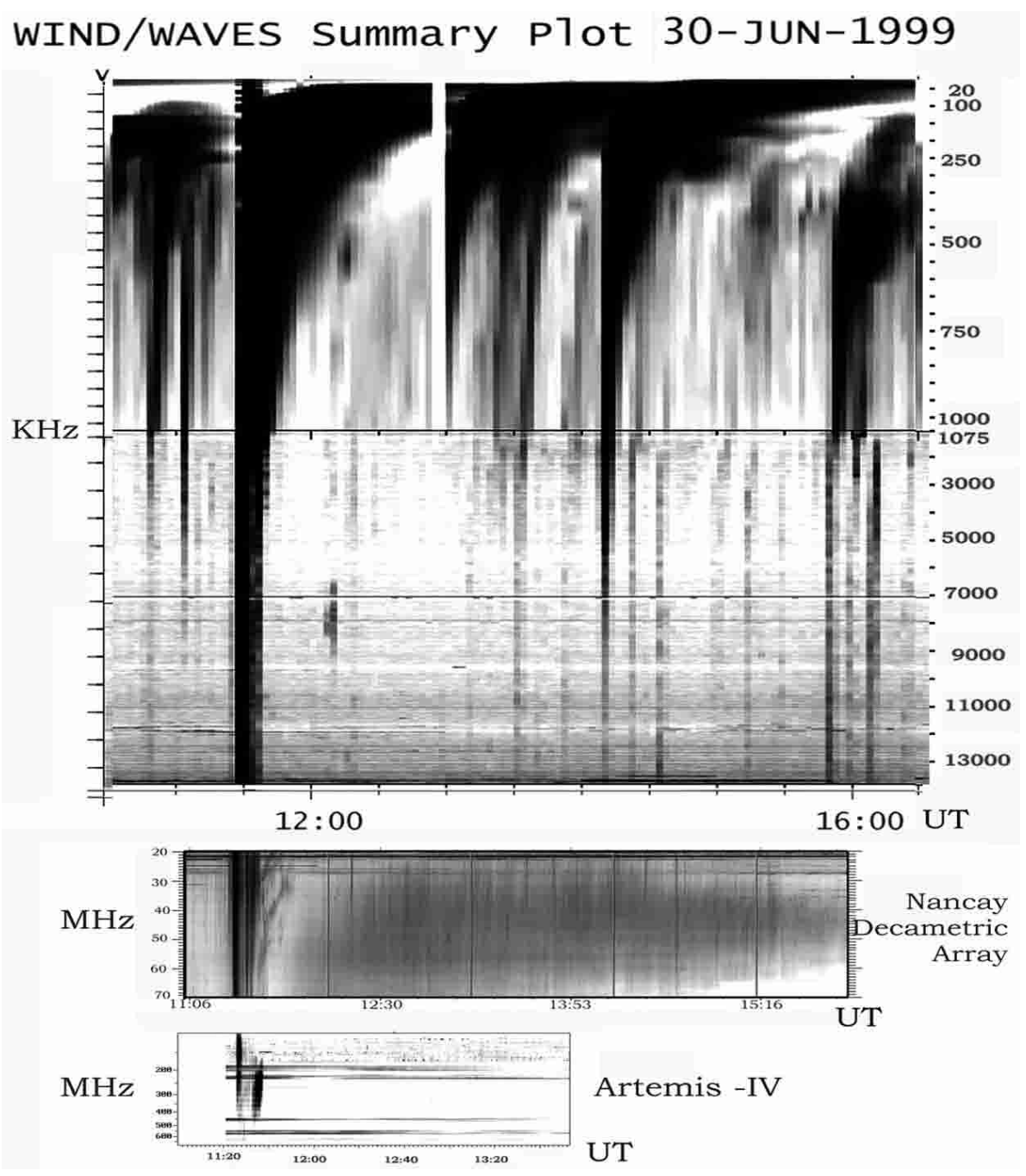

Fig. 3. Composite dynamic spectrum of the 1999 June 30 type II/IV event (\#18 in our catalog), preceded by a type III group, in the frequency range $687 \mathrm{MHz}$ to $1 \mathrm{KHz}$ with $18 \mathrm{~s}$ time resolution. Upper panel: WIND/WAVES spectrum, showing the type III in the interplanetary space; Middle panel: Nançay Decametric Array spectrum; Lower panel: ARTEMIS-IV ASG spectrum (cf. Fig. 4).

At this point we note that for a number of events the spatial criterion fails to lead to the acceptance or rejection of an association. This is due to either the lack of positional data for the radio burst or the flare or to the appearance of more than one accompanying flares as candidates for association. As regards the use of time window for temporal association, as already pointed out by Webb \& Hundhausen (1987), it represents a compromise between rejection of significant associations and inclusion of spurious ones, as for every threshold-based selection process. To mediate this effect we use the above-mentioned combination of criteria.

\section{Results}

In the table of the appendix we include all solar type II and IV radio bursts recorded by ARTEMIS-IV in the $110-687 \mathrm{MHz}$ range, during 1998-2000; we present the type II and IV burst parameters as well as the parameters of the associated CMEs, $\mathrm{H} \alpha$ flares and SXR GOES flares.

Forty events were recorded by ARTEMIS-IV in the period 1998-2000, of which 8 type IV continua, 11 type II bursts and 21 type II bursts followed by a type IV continuum (Type II/IV). Among the type II/IV were the radio signatures of the July 14, 2000 major solar event (event 36; see Klein et al. 2001; Caroubalos et al. 2001b), the May 2, 1998 event (event 06; see Pohjolainen et al. 2001) and four radio rich CMEs (i.e. CMEs associated with a metric or decametric type II burst) from Gopalswamy et al. (2000) (their Table 1). The gross spectral characteristics and the associated CME and flare parameters are summarised in the appendix. We note that all but one of the forty events were associated with either an $\mathrm{H} \alpha$ and/or a SXR (GOES) event. With regard to the CME-type II and CME-type IV association, our sample of event shows that:

- five out of eleven type II bursts were associated with a CME (45\%);

- five out of eight type IV bursts $(71 \%)$ were associated with a CME, while one occurred during a LASCO Data Gap;

- fifteen of the twenty one type II/IV events were associated with a CME $(79 \%)$ while two occurred during a LASCO data gap; 

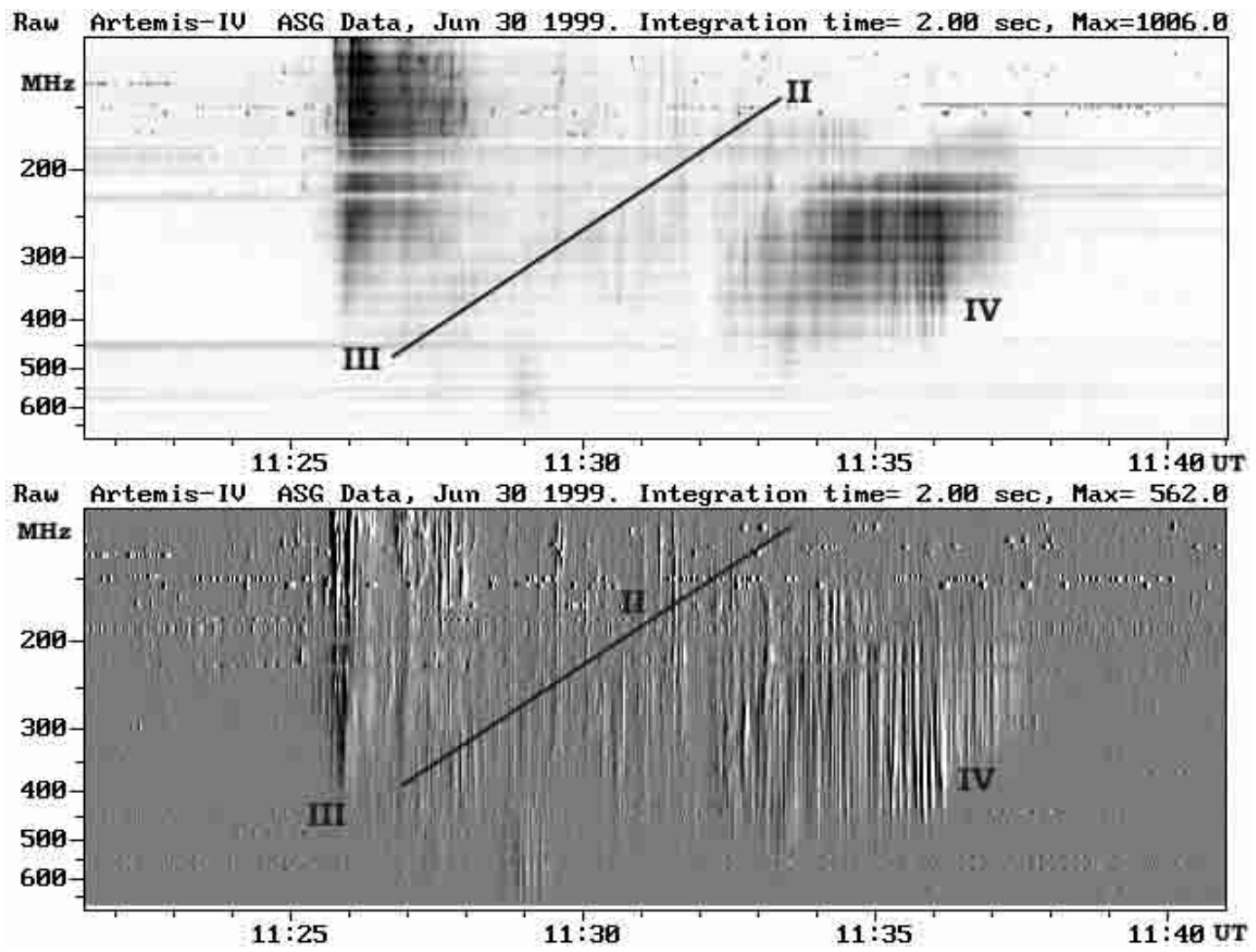

Fig. 4. Expanded ASG dynamic spectrum of the event shown in Fig. 3, with time resolution of $2.0 \mathrm{~s}$. The bursts of different types have been annotated on the figure. Upper panel: intensity spectrum, Lower panel: differential spectrum (time derivative of intensity).

- twenty of the thirty two type II and II/IV bursts were accompanied by CMEs (67\%) while two occurred during a LASCO data gap. This corroborates similar results by Sheeley et al. (1984) and Classen \& Aurass (2002); they indicate a $70 \%$ association probability between type II events and CMEs;

- twenty of the twenty nine type IV and II/IV bursts were associated with CMEs (77\%), while three occurred during LASCO data gaps;

- the type II associated CMEs have an average velocity of $(835 \pm 380) \mathrm{km} \mathrm{s}^{-1}$, while the CMEs not associated with type IIs have an average velocity of $(500 \pm 150) \mathrm{km} \mathrm{s}^{-1}$.

In Fig. 6 we compare velocities of CMEs and associated type II drift velocities. To take into account all errors in the estimation of both, we adopted the criterion introduced by Classen \& Aurass (2002), which states that, a velocity ratio in the $1 / 2-2$ range may qualify the type II MHD shock as originating in the CME front (class 2 event); all but three of the CME associated type IIs in our data set seem to belong in this category.

In Fig. 7 we show histograms of velocities of CMEs associated with type II events as well as of CMEs not associated with type IIs. The former have an average velocity of $(835 \pm 380) \mathrm{km} \mathrm{s}^{-1}$ while the latter of $(500 \pm 150) \mathrm{km} \mathrm{s}^{-1}$. Similar results are reported by Gopalswamy et al. (2000) who maintain that radio rich CMEs tend to be faster than average. The systematically lower velocity range, yet with some overlap, for the non type II associated CMEs implies that, although a relatively fast CME may be required for the formation of a MHD shock, still ambient medium parameters (density and magnetic field) are equally important since the CME needs exceed the Alfven velocity.

In Fig. 8 we present velocities of CMEs versus the total integrated flux of the associated SXR flare (1-8 A GOES channel); the velocity increases with increasing total SXR flare output, approximately following the empirical relationship $V_{\mathrm{CME}}=150 \ln \left(F_{\mathrm{SXR}}\right)+1384$; this may imply a certain correlation between the extent of the magnetic restructuring linked to a CME launch and the extent of the reconnection releasing the free energy necessary for a flare. However, a cause and effect mechanism cannot be observationally established under the circumstances.

In Fig. 9 we summarize the total activity, including estimated CME take off time, SXR flare and type II, III and IV metric radio bursts, of the CME associated events of the ARTEMIS-IV catalogue. The origin of time coincides, for each event, with the time of the SXR flare maximum. We note that most of the CME launch times precede by 5-60 min (average $30 \mathrm{~min}$ ) the SXR peak, and in most bursts the onset of the radio bursts. Type III groups precede most CME associated type II and type II/IV bursts.

\section{Summary and conclusions}

The Artemis-IV catalogue of type II, IV and II/IV events recorded during 1998-2000 includes information on associated CMEs and flares; the examination of these data has provided us with some interesting statistical results. 


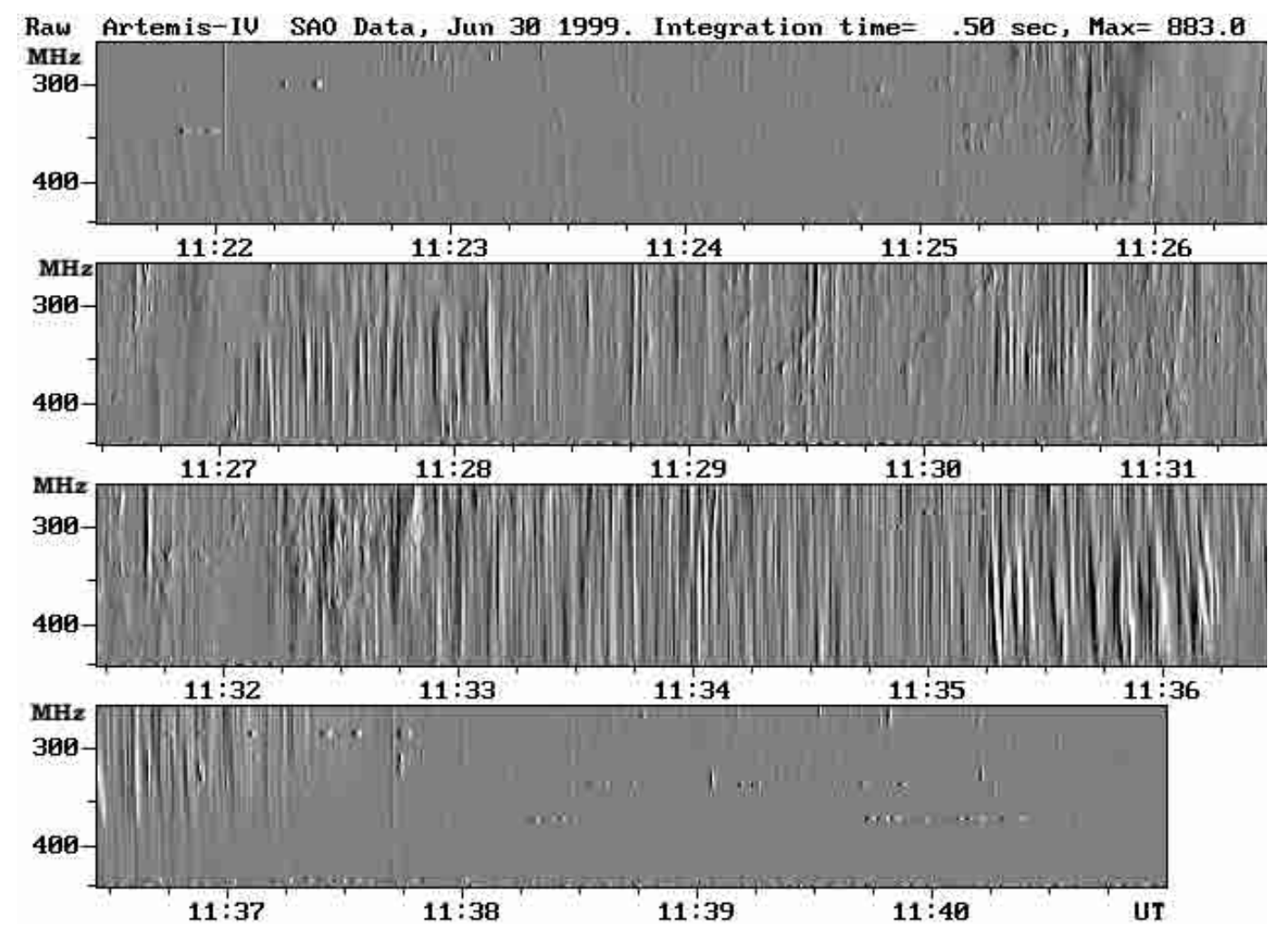

Fig. 5. SAO differential spectrum of the 1999 June 30 type II/IV event (shown in Figs. 3 and 4), with time resolution 0.5 s. Intermediate drift bursts (fibers, see for example 11:29-11:31 UT) and pulsations have been enhanced by the differentiation which has suppressed the underlying continuum.

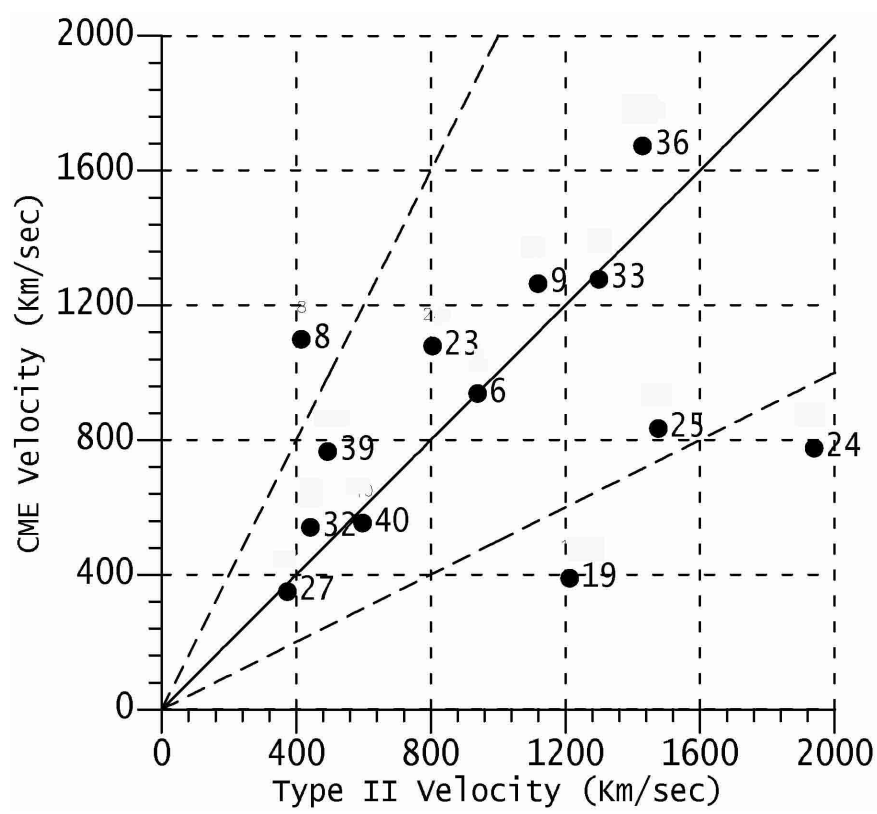

Fig. 6. Velocities of CMEs in $\mathrm{km} \mathrm{s}^{-1}\left(V_{\mathrm{CME}}\right)$ versus drift velocities of associated type II bursts $\left(V_{\text {drift }}\right)$ in $\mathrm{km} \mathrm{s}^{-1}$. The lines mark: $V_{\mathrm{CME}}=$ $2 V_{\text {drift }}, V_{\mathrm{CME}}=V_{\text {drift }}, 2 V_{\mathrm{CME}}=V_{\text {drift }}$; a type II velocity in this range probably qualifies the MHD shock as piston driven by the CME front (see text).

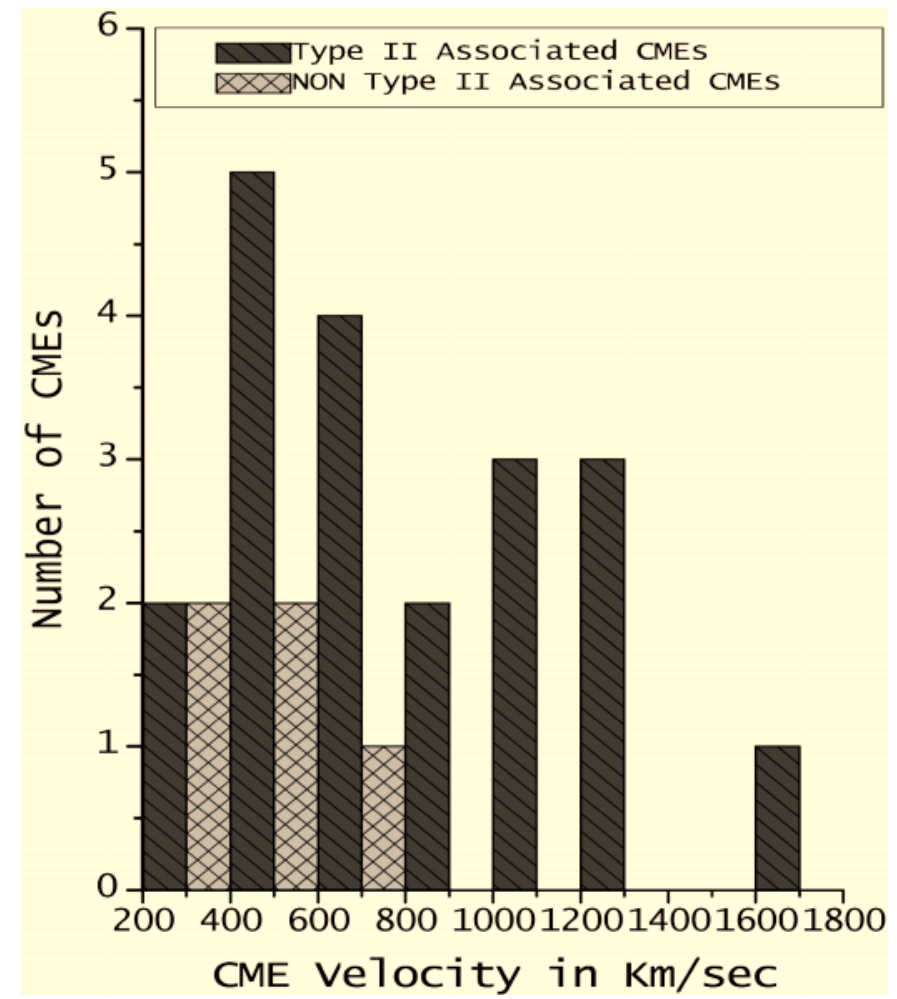

Fig. 7. Velocity histograms of type II associated CMEs and CMEs without a type II association. 


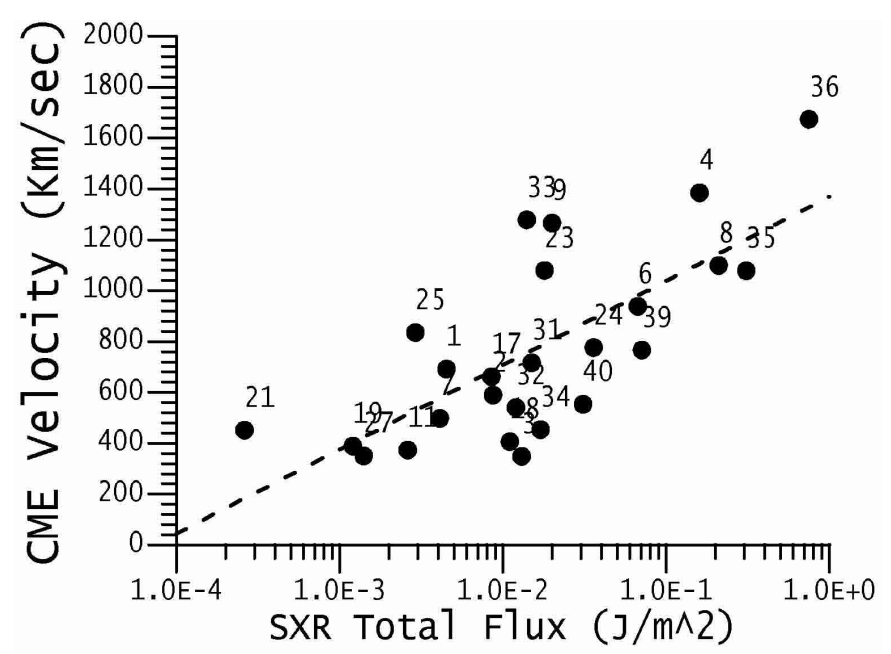

Fig. 8. Velocities of CMEs in $\mathrm{km} \mathrm{s}^{-1}\left(V_{\mathrm{CME}}\right)$ versus integrated flux $\left(F_{\text {SXR }}\right)$ of associated SXR flares in $\mathrm{J} / \mathrm{m}^{2}$. The data are fitted with $V_{\mathrm{CME}}=150 \ln \left(F_{\mathrm{SXR}}\right)+1384$.

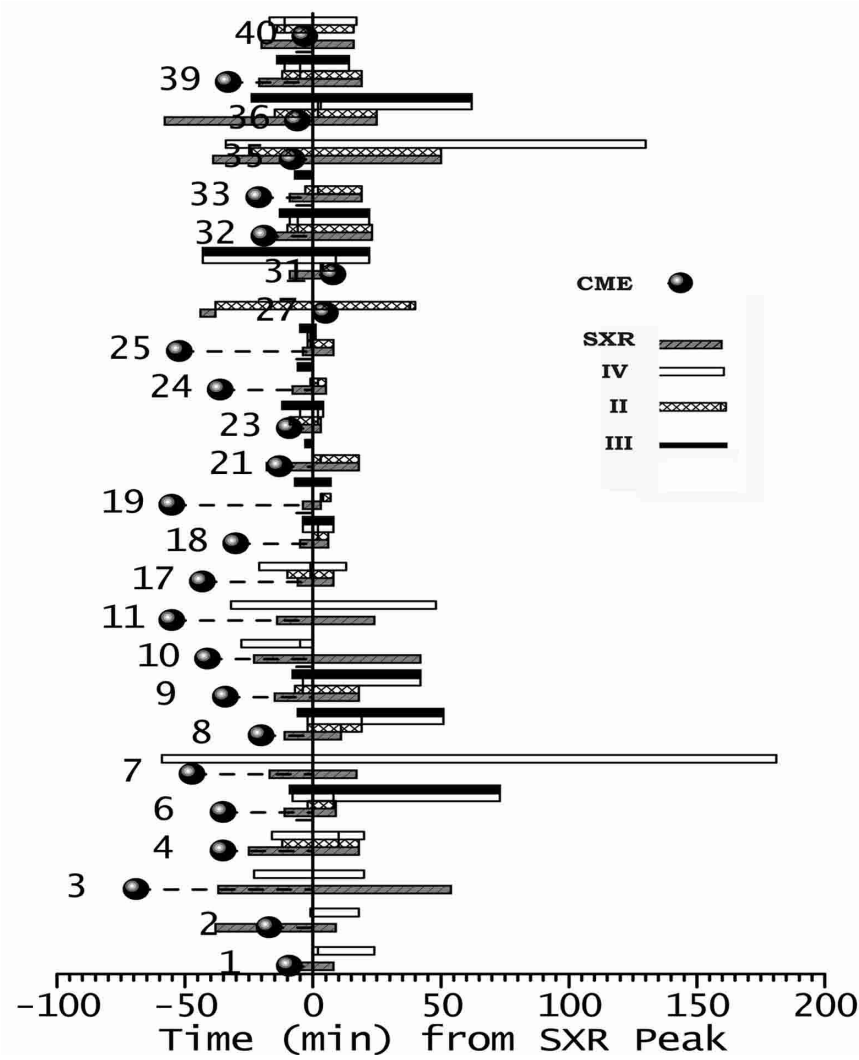

Fig. 9. Schematic representation of the total activity of the CME associated events. It depicts durations of SXR flares, Type III, II, IV activity and extrapolated CME launch time; all times are measured from the SXR flare peak.

All but one of the catalogued events were flare-associated; $68 \%$ were also CME-associated. Most (92\%) of the CME take off times precede the associated SXR peak flux (GOES Channel 1-8 A) by 30 min on the average, while an important fraction (72\%) also precedes the flare onset. Previous observations (Andrews 2001) maintain that the estimated CME launch precedes or follows, within $40 \mathrm{~min}$, the SXR flare onset which does not contradict our statistic. Furthermore, our results are in accordance with a previous case study on four CME associated flares by Zhang et al. (2001), who stated that the initial acceleration phase of a CME coincides with the rise phase of the accompanying SXR flare, thus supporting a CME triggering of the flare scenario.

Of the type II bursts in our list, $67 \%$ are associated with CMEs. This corroborates the observations of Sheeley et al. (1984), Classen \& Aurass (2002) who reported that $70 \%$ of type II bursts are associated with CMEs; they also pointed out that majority of the type II associated CMEs have velocities greater than $400 \mathrm{~km} \mathrm{~s}^{-1}$ which is the case with our data set; this is also in accordance with Gopalswamy et al. (2001) whose data point out that the faster CMEs drive type II busts, resulting in radio rich events.

Lastly, our results imply that type IV and composite type II/IV bursts manifest an even better association with CMEs (77\% and 79\% respectively) than type II bursts alone, thus providing a more reliable proxy for the CME onset.

Acknowledgements. This work was financially supported by the Research Committee of the University of Athens. The LASCO CME catalogue is generated and maintained by the Center for Solar Physics and Space Weather, The Catholic University of America in cooperation with the Naval Research Laboratory and NASA. SOHO is a project of international cooperation between ESA and NASA. The Solar Geophysical Data Catalogue is compiled and maintained by the US Department of Commerce. The authors wish to thank the anonymous referee for a number of extremely useful suggestions and comments on the first draft of this article.

\section{References}

Amari, T., Luciani, J. F., Mikic, Z., \& Linkre, J. 2000, ApJ, 529, L49 Andrews, M. D. 2001, AGU Fall Meeting, Abstract SH42A-0766

Aurass, H. 1997, Coronal Physics from Radio and Space Observations; Proceedings of the CESRA Workshop 3-7 June 1996, ed. G. Trottet, Springer Lecture Notes in Physics, 483, 135

Aurass, H., Vourlidas, A., Andrews, M. D., et al. 1999, ApJ, 511, 451

Bastian, T. S., Pick, M., Kedraon, A., Maia, D., \& Vourlidas, A. 2001, ApJ, 558, L65

Boischot, A. C. R. 1957, Acad. Sci. Paris, 244, 1326

Bougeret, J.-L., Zarka, P., Caroubalos, C., et al. 1998, GeoRL., 25, 2513

Brueckner, G. E., Howard, R. A., Koomen, M. J., et al. 1995, Sol. Phys., 162, 357

Caroubalos, C., Maroulis, D., Patavalis, N., et al. 2001, Exp. Astron., 11,23

Caroubalos, C., Alissandrakis, C., Hillaris, A., et al. 2001, Sol. Phys., 204, 165

Classen, H. T., \& Aurass, H. 2002, A\&A, 384, 1098

Gil Moreno, G., Mendez Berhondo, A., \& Rodriguez-Taboada, R. E. 1998, New Astron., 3, 335

Gopalswamy, N., Kaiser, M., Thompson, B. J., et al. 2000, GRL., 27, 1427

Gopalswamy, N., Yashiro, S., Kaiser, M. L., Howard, R. A., \& Bougeret, J.-L. 2001, JGR., 106, 29219

Gilbert, H. R., Holzer, T. E., Burkepile, J. T., \& Hundhausen, A. J. 2000, ApJ, 537, 503

Guiping Zhou, Jinxiu Wang, \& Zhuolian Cao 2003, A\&A, 397, 1057

Hildner, E., Gosling, J. T., McQueen, R. M., et al. 1976, Sol. Phys., 48,127 
Kahler, S. W., Sheeley, N. R. Jr., Howard, R. A., Koomen, M. J., \& Michels 1984, Sol. Phys., 93, 133

Kahler, S. W., Sheeley, N. R., Jr., \& Liggett, M. 1989, ApJ, 344, 1026

Kedraon, A., \& Delouis, J. M. 1997, Coronal Physics from Radio and Space Observations, ed. G. Trottet (Berlin: Springer), 193

Klassen, A., Aurass, H., Klein, K.-L., Hoffman, A., \& Mann, G. 1999, A\&A, 343, 287

Klassen, Bothmer, V. A., Mann, G., Reiner, M. J., et al. 2002, A\&A, 385,1078

Klein, K.-L., Khan, J., Vilmer, N., Delouis, J.-M., \& Aurass, H. 1999, A\&A, 346, L53

Klein, K.-L., Trottet, G., Lantos, P., \& Delabourdiniere, J.-P. 2001, A\&A, 373, 1073

Klein, K.-L., \& Mouradian, Z. 2002, A\&A, 381, 683

Kundu, M. R., Nindos, A., Vilmer, N., et al. 2001, ApJ, 559, 443

Maia, D., Pick, M., Vourlidas, A., \& Howard, R. 2000, ApJ, 528, L49

Mann, G., Aurass, H., Paschke, J., \& Voigt, W. 1992, ESA-Journal, 348,129

Mann, G., Klassen, A., Classen, H.-T., et al. 1996, A\&AS, 119, 489

Maxwell, A., \& Thompson, A. R. 1962, ApJ, 135, 138

Munro, R. H., Gosling, J. T., Hildner, E., et al. 1979, Sol. Phys., 61, 201,

Newkirk, G. 1961, ApJ, 133, 983

Newkirk, G. 1967, ARA\&A, 5, 213

Pearson, D. H., Nelson, R., Kojoian, G., \& Seal, J. 1989, ApJ, 336, 1050
Pohjolainen, S., Maia, D., Pick, M., et al. 2001, ApJ, 556, 421

Robinson, R. D. 1985, Sol. Radiophys., ed. D. J. McLean, \& N. Labrum (Cambridge University Press), 137

Sheeley, N., Stewart, R. T., Robinson, R. D., et al. 1984, ApJ, 279, 389

Slottje, C. 1981, Atlas of Fine Structures of Dynamic Spectra of Solar Type IV-dm and Some Type II Radio Bursts. N.F.R.A Dwingeloo and Astronomical Institute of Utrecht

Stewart, R. T. 1985, Sol. Radiophys., ed. D. J. McLean, \& N. Labrum (Cambridge University Press), 361

Svestka, Z. 2001, Space Sci. Rev., 95, 135

Tlamicha, A., \& Karlicky, M. 1976, BAICz, 27, 6

Vrsnak, B., Magdalenic, J., \& Aurass, H. 2001, Sol. Phys., 202, 319

Vourlidas, A., Subramanian, P., Dere, K. P., \& Howard, R. A. 2000, ApJ, 534, 456

Webb, D. F., \& Hundhausen, A. J. 1987, Sol. Phys., 108, 383

Wild, J. P., \& Smerd, S. F. 1972, ARA\&A, 10, 159

Wild, J. P., Smerd, S. F., \& Weiss, A. A. 1963, ARA\&A, 1, 291

Wu, S. T., Andrews, M. D., \& Plunkett, S. P. 2001, Space Sci. Rev., 95, 191

Yashiro, S., Gopalswamy, N., St. Cyr, O. C., et al. 2001, AGU Spring Meeting, Abstract SH31C-10

Zhang, J., Dere, K. P., Howard, R. A., Kundu, M. R., \& White, S. M. 2001, ApJ, 559, 452 


\section{Online Material}




\section{Appendix A: ARTEMIS-IV, LASCO, GOES and $\mathrm{H} \alpha$ Observations}

The table provides a concise summary of metric bursts (type II, IV and II/IV events), with their associated CMEs and SXR-H $\alpha$ flares, in the 1998-2000 period.

In Col. 1 the table gives the type of activity. Under the heading "associated bursts" we included all bursts of the type III family preceding type II, IV and II/IV events, as well as "arcs" and "precursors". In parenthesis, next to $\mathrm{H} \alpha$, is the reporting station. Column 2 gives the date and start time of the events; for CMEs and type II bursts recorded by ARTEMIS-IV we have included the extrapolated launch time as specified in the "event list section", together with the time of the first detection; for the CMEs the time of first detection is the time of the first appearance in the field of view of the LASCO/C2 Coronagraph. In Col. 3 we give the peak time of SXR and $\mathrm{H} \alpha$ flares and in Col. 4 the end times of bursts and flares.

Column 5 gives the flare class (B, C, M, X for the SXR; SF, $\mathrm{SN}, \ldots, 3 \mathrm{~B}$ for $\mathrm{H} \alpha$, from SGD) and Col. 6 the SXR integrated flux. In Col. 7 we give the location of the flare on the disk, in heliographic coordinates, as well as the central position angle and the width (entry underneath the position angle) of the CME. Column 8 shows the frequency range of radio bursts in $\mathrm{MHz}$, while Col. 9 gives the logarithmic frequency drift of the type II bursts. Column 10 gives the drift velocities of type II bursts, calculated from the frequency drift rate and a Newkirk coronal density model assuming radial propagation (cf. Sect. 2.2) and the CME velocities from the LASCO lists, estimated by linear regression (Yashiro et al. 2001). In Col. 11 we give the CME acceleration from the same LASCO lists.

In the remarks column we provide information on the fine structure of type IV continua, from the SAO dynamic spectra; we also mark the type IIs which were outside the ARTEMIS-IV spectral range and the relevant information has been taken from the AIP, Izmiran or Nançay Decametric Array archives. In addition, we give information about the solar active region associated with each burst. For the radio bursts with imaging data from the Nançay radioheliograph, ensuring an "excellent" association with the accompanying $\mathrm{H} \alpha$ flare, we record the NOAA number of the region of origin. Bursts without a NOAA region entry in this column, for lack of positional information, are only deemed in "good" association with the accompanying activity. 
C. Caroubalos et al.: ARTEMIS-IV type II/IV observations during 1998-2000, Online Material p 3

Table A.1. ARTEMIS-IV Observations and Associated LASCO, SXR \& H $\alpha$ Events.

\begin{tabular}{|c|c|c|c|c|c|c|c|c|c|c|c|}
\hline \multirow[t]{2}{*}{ Observation } & \multirow[t]{2}{*}{ UT } & \multirow[t]{2}{*}{ UT } & \multirow[t]{2}{*}{ UT } & \multirow[t]{2}{*}{ Class } & $\begin{array}{l}\text { Integ } \\
\text { Flux }\end{array}$ & \multirow[t]{2}{*}{ Location } & \multirow{2}{*}{$\begin{array}{l}\text { Freq } \\
\text { Range } \\
\mathrm{MHz}\end{array}$} & \multirow{2}{*}{$\begin{array}{l}\text { Drift } \\
\frac{1}{f} \frac{\mathrm{d} f}{\mathrm{~d} t} \\
\mathrm{~s}^{-1}\end{array}$} & \multirow[t]{2}{*}{$\begin{array}{l}\text { Vel } \\
\mathrm{km} \mathrm{s}^{-1}\end{array}$} & \multirow[t]{2}{*}{$\begin{array}{l}\text { Accel } \\
\mathrm{m} / \mathrm{s}^{2}\end{array}$} & \multirow[t]{2}{*}{ Remarks } \\
\hline & & & & & $\mathrm{J} / \mathrm{m}^{2}$ & & & & & & \\
\hline Event 01: & 15 April & 1998 & & & & & & & & & \\
\hline \multirow[t]{3}{*}{ Type IV } & $07: 48$ & - & $08: 10$ & IV & - & - & $200-550$ & - & - & - & Pulsations \\
\hline & & & & & & & & & & & Some Fibers \\
\hline & & & & & & & & & & & NOAA 8203 \\
\hline \multirow[t]{2}{*}{ CME } & $07: 37$ & - & - & - & - & 335 & - & - & 691 & -6.0 & - \\
\hline & $07: 55$ & & & & & 049 & & & & & \\
\hline SXR & $07: 37$ & $07: 46$ & $07: 54$ & $\mathrm{C} 8.8$ & $4.5 \times 10^{-3}$ & - & - & - & - & - & NOAA 8203 \\
\hline $\mathrm{H} \alpha(\mathrm{SVI})$ & 07:39 & $07: 45$ & 08:06 & $\mathrm{SN}$ & - & N29W15 & - & - & - & - & NOAA 8203 \\
\hline Event 02: & 15 April & 1998 & & & & & & & & & \\
\hline \multirow[t]{2}{*}{ Type IV } & $12: 32$ & - & $12: 51$ & IV & - & - & $668 x-200$ & - & - & - & Pulsations \\
\hline & & & & & & & & & & & NOAA 8203 \\
\hline \multirow[t]{2}{*}{ CME } & $12: 16$ & - & - & - & - & 339 & - & - & 589 & -7.0 & - \\
\hline & $13: 55$ & & & & & 048 & & & & & \\
\hline SXR & $11: 55$ & $12: 33$ & $12: 42$ & $\mathrm{C} 8.2$ & $8.7 \times 10^{-3}$ & - & - & - & - & - & NOAA 8203 \\
\hline $\mathrm{H} \alpha(\mathrm{SVI})$ & $12: 01$ & $12: 23$ & $12: 45$ & SF & - & N27W19 & - & - & - & - & NOAA 8203 \\
\hline Event 03: & 25 April & 1998 & & & & & & & & & \\
\hline \multirow[t]{2}{*}{ Type IV } & $14: 16$ & - & $14: 59 x$ & IV & - & - & $110 x-450$ & - & - & - & Pulsations \\
\hline & & & & & & & & & & & NOAA 8210 \\
\hline \multirow[t]{2}{*}{ CME } & $13: 30$ & - & - & - & - & 095 & - & - & 349 & -5.5 & - \\
\hline & $15: 11$ & & & & & 073 & & & & & \\
\hline SXR & $14: 02$ & $14: 39$ & $15: 33$ & C3.6 & $1.3 \times 10^{-2}$ & - & - & - & - & - & NOAA 8210 \\
\hline $\mathrm{H} \alpha(\mathrm{KANZ})$ & $14: 14$ & $14: 22$ & $15: 32$ & $\mathrm{SF}$ & - & S15E70 & - & - & - & - & NOAA 8210 \\
\hline Event 04: & 27 April & 1998 & & & & & & & & & \\
\hline Type IV & 09:04 & - & $09: 40$ & IV & - & - & $100 x-500$ & - & - & - & Pulsations \\
\hline Type II & 09:08 & - & $09: 30$ & II & - & - & $40 x-90$ & - & - & - & From AIP \\
\hline \multirow[t]{2}{*}{ CME } & $08: 45$ & - & - & - & - & Halo & - & - & 1385 & 74.5 & - \\
\hline & $08: 56$ & & & & & - & & & & & \\
\hline SXR & $08: 55$ & 09:20 & $09: 38$ & $\mathrm{X} 1.0$ & $1.6 \times 10^{-1}$ & - & - & - & - & & NOAA 8210 \\
\hline $\mathrm{H} \alpha(\mathrm{SVI})$ & $08: 36$ & 09:11 & $12: 34$ & $2 \mathrm{~B}$ & - & S16E50 & - & - & - & - & NOAA 8210 \\
\hline Event 05: & 27 April & 1998 & & & & & & & & & \\
\hline Type IV & $10: 25$ & - & $11: 25$ & IV & - & - & $150-400$ & - & - & - & Pulsations \\
\hline
\end{tabular}


C. Caroubalos et al.: ARTEMIS-IV type II/IV observations during 1998-2000, Online Material p 4

Table A.1. continued.

\begin{tabular}{|c|c|c|c|c|c|c|c|c|c|c|c|}
\hline \multirow[t]{2}{*}{ Observation } & \multirow[t]{2}{*}{ UT } & \multirow[t]{2}{*}{ UT } & \multirow[t]{2}{*}{ UT } & Class & \multirow{2}{*}{\multicolumn{2}{|c|}{$\begin{array}{l}\text { Flux } \\
\mathrm{J} / \mathrm{m}^{2}\end{array}$}} & $\begin{array}{l}\text { Freq } \\
\text { Range }\end{array}$ & $\begin{array}{l}\text { Drift } \\
\frac{1}{f} \frac{\mathrm{d} f}{\mathrm{~d} t}\end{array}$ & \multirow[t]{2}{*}{$\mathrm{km} \mathrm{s}^{-1}$} & \multirow[t]{2}{*}{$\mathrm{m} / \mathrm{s}^{2}$} & Remarks \\
\hline & & & & & & & $\mathrm{MHz}$ & $\mathrm{s}^{-1}$ & & & \\
\hline Event 06: & 2 May & 1998 & & & & & & & & & \\
\hline \multirow[t]{2}{*}{ Type II } & $13: 40$ & - & $13: 50$ & II & - & - & $300-110 x$ & 0.0036 & 940 & - & Harmonic \\
\hline & $13: 36$ & & & & & & & & & & NOAA 8210 \\
\hline \multirow[t]{2}{*}{ Type IV } & $13: 34$ & - & $14: 55$ & IV & - & - & $110 x-698$ & - & - & - & Pulsations \\
\hline & & & & & & & & & & & NOAA 8210 \\
\hline \multirow[t]{3}{*}{ Ass. Bursts } & $13: 33$ & - & $13: 40$ & III & - & - & $600-110 x$ & - & - & - & GG \\
\hline & & & & & & & & & & & NOAA 8210 \\
\hline & & & & & & & & & & & NOAA 8214 \\
\hline \multirow[t]{2}{*}{ CME } & 13:07 & - & - & - & - & Halo & - & - & 938 & -29.0 & - \\
\hline & $14: 06$ & & & & & - & & & & & \\
\hline SXR & $13: 31$ & $13: 42$ & $13: 51$ & $\mathrm{X} 1.1$ & $6.7 \times 10^{-2}$ & - & - & - & - & - & NOAA 8210 \\
\hline SXR & $13: 14$ & $13: 17$ & $13: 19$ & B6.5 & $1.7 \times 10^{-4}$ & N25E26 & - & - & - & - & NOAA 8214 \\
\hline $\mathrm{H} \alpha$ (RAMY) & $13: 34$ & $13: 42$ & $15: 47$ & $3 \mathrm{~B}$ & - & S15W15 & - & - & - & - & NOAA 8210 \\
\hline $\mathrm{H} \alpha(\mathrm{HOL})$ & $13: 18$ & $13: 23$ & $13: 36$ & $\mathrm{SF}$ & - & N25E26 & - & - & - & - & NOAA 8214 \\
\hline Event 07: & 3 May & 1998 & & & & & & & & & \\
\hline \multirow[t]{2}{*}{ Type IV } & $09: 20$ & - & $13: 20$ & IV & - & - & $110 x-500$ & - & - & - & Pulsations \\
\hline & & & & & & & & & & & NOAA 8210 \\
\hline \multirow[t]{2}{*}{$\mathrm{CME}$} & $09: 32$ & - & - & - & - & 241 & - & - & 497 & -2.5 & - \\
\hline & $10: 30$ & & & & & 074 & & & & & \\
\hline SXR & 10:02 & $10: 19$ & $10: 36$ & $\mathrm{C} 2.5$ & $4.1 \times 10^{-3}$ & - & - & - & - & - & NOAA 8210 \\
\hline $\mathrm{H} \alpha$ (RAMY) & $10: 14$ & $10: 15$ & $10: 45$ & SN & - & S20W26 & - & - & - & - & NOAA 8210 \\
\hline Event 08: & 6 May & 1998 & & & & & & & & & \\
\hline \multirow[t]{2}{*}{ Type II } & 08:07 & - & $08: 28$ & II & - & - & $300-110$ & 0.0016 & 416 & - & $\mathrm{F}-\mathrm{H}$ \\
\hline & $07: 57$ & & & & & & & & & & NOAA 8210 \\
\hline Type IV & 08:07 & - & 09:00 & IV & - & - & $400-110 x$ & - & - & - & NOAA 8210 \\
\hline \multirow[t]{3}{*}{ Ass. Bursts } & 08:03 & - & 08:05 & III & - & - & $400-110$ & - & - & - & $\mathrm{G}$ \\
\hline & 08:05:40 & - & 08:06:50 & III & - & - & $300-350$ & - & - & - & Arc \\
\hline & & & & & & & & & & & NOAA 8210 \\
\hline \multirow[t]{2}{*}{ CME } & $07: 50$ & - & - & - & - & 309 & - & - & 1100 & 24.5 & - \\
\hline & 08:29 & & & & & 190 & & & & & \\
\hline SXR & $07: 58$ & 08:09 & 08:20 & $\mathrm{X} 2.7$ & $2.1 \times 10^{-1}$ & - & - & - & - & - & NOAA 8210 \\
\hline $\mathrm{H} \alpha(\mathrm{COM})$ & $07: 58$ & 08:04 & 09:05 & $1 \mathrm{~N}$ & - & S11W65 & - & - & - & - & NOAA 8210 \\
\hline
\end{tabular}


C. Caroubalos et al.: ARTEMIS-IV type II/IV observations during 1998-2000, Online Material p 5

Table A.1. continued.

\begin{tabular}{|c|c|c|c|c|c|c|c|c|c|c|c|}
\hline Observation & $\begin{array}{l}\text { Start } \\
\text { UT }\end{array}$ & $\begin{array}{l}\text { Peak } \\
\text { UT }\end{array}$ & $\begin{array}{l}\text { End } \\
\text { UT }\end{array}$ & Class & $\begin{array}{l}\text { Integ } \\
\text { Flux } \\
\mathrm{J} / \mathrm{m}^{2}\end{array}$ & Location & $\begin{array}{l}\text { Freq } \\
\text { Range } \\
\mathrm{MHz}\end{array}$ & $\begin{array}{l}\text { Drift } \\
\frac{1}{f} \frac{\mathrm{d} f}{\mathrm{~d} t} \\
\mathrm{~s}^{-1}\end{array}$ & $\begin{array}{l}\mathrm{Vel} \\
\mathrm{km} \mathrm{s}^{-1}\end{array}$ & $\begin{array}{l}\text { Accel } \\
\mathrm{m} / \mathrm{s}^{2}\end{array}$ & Remarks \\
\hline Event 09: & 08 May & 1998 & & & & & & & & & \\
\hline Type II & $\begin{array}{l}06: 01 \\
05: 57\end{array}$ & - & 06:04 & II & - & - & $250-110 x$ & 0.0043 & 1120 & - & Harmonic \\
\hline Type IV & 06:04 & - & $06: 50$ & IV & - & - & $350-110$ & - & - & - & Pulsations \\
\hline Ass. Bursts & 06:00:30 & - & 06:02 & III & - & - & $300-180$ & - & - & - & $\mathrm{U}$ or ARC \\
\hline CME & $\begin{array}{l}05: 34 \\
06: 27\end{array}$ & - & - & - & - & $\begin{array}{l}245 \\
075\end{array}$ & - & - & 1265 & -62.0 & $\begin{array}{l}- \\
-\end{array}$ \\
\hline SXR & $05: 53$ & 06:08 & $06: 26$ & M1.4 & $2.0 \times 10^{-2}$ & - & - & - & - & - & - \\
\hline $\mathrm{H} \alpha(\mathrm{KANZ})$ & $06: 19$ & $06: 24$ & $06: 36$ & $\mathrm{SF}$ & - & N23W57 & - & - & - & - & NOAA 8214 \\
\hline $\mathrm{H} \alpha$ (KANZ) & 06:19 & $06: 28$ & 07:00 & SF & - & S18W82 & - & - & - & - & NOAA 8210 \\
\hline Event 10: & 27 May & 1998 & & & & & & & & & \\
\hline Type IV & 13:07 & - & $13: 30$ & IV & - & - & $698 x-110 x$ & - & - & - & NOAA 8226 \\
\hline Type II & 13:02 & - & $15: 47$ & II & - & - & $70-20$ & - & - & - & Nançay \\
\hline CME & $\begin{array}{l}12: 54 \\
13: 46\end{array}$ & - & - & - & - & $\begin{array}{l}306 \\
268\end{array}$ & - & - & 878 & -4.0 & $\begin{array}{l}- \\
-\end{array}$ \\
\hline SXR & $13: 30$ & $13: 35$ & $14: 50$ & C7.5 & $3.0 \times 10^{-2}$ & - & - & - & - & - & NOAA 8226 \\
\hline $\mathrm{H} \alpha(\mathrm{HOL})$ & $13: 25$ & $13: 38$ & $15: 19$ & SF & - & N18W58 & - & - & - & - & NOAA 8226 \\
\hline Event 11: & 19 June & 1998 & & & & & & & & & \\
\hline Type IV & $06: 39$ & - & $07: 59$ & IV & - & - & $110 x-698 x$ & - & - & - & $\begin{array}{l}\text { Pulsations } \\
\text { NOAA } 8249\end{array}$ \\
\hline CME & $\begin{array}{l}06: 16 \\
07: 20\end{array}$ & - & - & - & - & $\begin{array}{l}128 \\
105\end{array}$ & - & - & 373 & 5.5 & - \\
\hline SXR & $06: 48$ & $07: 11$ & $07: 53$ & B85 & $2.6 \times 10^{-3}$ & - & - & - & - & - & NOAA 8249 \\
\hline $\mathrm{H} \alpha$ (LEAR) & $06: 52$ & $06: 56$ & $07: 28$ & $\mathrm{SF}$ & - & S32E36 & - & - & - & - & NOAA 8249 \\
\hline Event 12: & 20 June & 1998 & & & & & & & & & \\
\hline Type IV & $14: 23$ & - & $15: 00 x$ & IV & - & - & $110 x-698 x$ & - & - & - & $\begin{array}{l}\text { Pulsations } \\
\text { NOAA } 8243\end{array}$ \\
\hline Type II & $14: 20$ & - & $14: 44$ & II & - & - & $40 x-150$ & - & - & - & From AIP \\
\hline SXR & $14: 12$ & $14: 30$ & $14: 44$ & $\mathrm{C} 4.0$ & $4.9 \times 10^{-3}$ & - & - & - & - & & NOAA 8243 \\
\hline $\mathrm{H} \alpha$ (KANZ) & $14: 19$ & $14: 27$ & $14: 47$ & $1 \mathrm{~F}$ & - & N13W23 & - & - & - & - & NOAA 8243 \\
\hline Event 13: & 30 Aug. & 1998 & & & & & & & & & \\
\hline Type IV & $06: 45$ & - & $07: 17$ & IV & - & - & $350-110$ & - & - & - & NOAA 8307 \\
\hline Ass. Bursts & $06: 46$ & - & $07: 17$ & III & - & - & $500-110 x$ & - & - & - & GG \\
\hline CME & LASCO & DATA & GAP & & & & & & & & - \\
\hline $\mathrm{H} \alpha$ (LEAR) & $06: 43$ & $06: 51$ & 07:07 & SF & - & N29W69 & - & - & - & - & NOAA 8307 \\
\hline
\end{tabular}


C. Caroubalos et al.: ARTEMIS-IV type II/IV observations during 1998-2000, Online Material p 6

Table A.1. continued.

\begin{tabular}{|c|c|c|c|c|c|c|c|c|c|c|c|}
\hline \multirow[t]{2}{*}{ Observation } & \multirow[t]{2}{*}{ UT } & $\begin{array}{l}\text { Peak } \\
\text { UT }\end{array}$ & \multirow[t]{2}{*}{ UT } & Class & \multirow{2}{*}{\multicolumn{2}{|c|}{$\begin{array}{l}\text { Flux } \\
\mathrm{J} / \mathrm{m}^{2}\end{array}$}} & $\begin{array}{l}\text { Freq } \\
\text { Range }\end{array}$ & $\begin{array}{l}\text { Drift } \\
\frac{1}{f} \frac{\mathrm{d} f}{\mathrm{~d} t}\end{array}$ & $\begin{array}{l}\text { Vel } \\
\mathrm{km} \mathrm{s}^{-1}\end{array}$ & \multirow[t]{2}{*}{$\mathrm{m} / \mathrm{s}^{2}$} & Remarks \\
\hline & & UT & & & & & $\mathrm{MHz}$ & $\mathrm{s}^{-1}$ & $\mathrm{~km} \mathrm{~s}^{-1}$ & & \\
\hline Event 14: & 23 Sep. & 1998 & & & & & & & & & \\
\hline \multirow[t]{2}{*}{ Type II } & $06: 56$ & - & 07:02 & II & - & - & $200-110 x$ & 0.0018 & 552 & - & Harmonic \\
\hline & $06: 44$ & & & & & & & & & & NOAA 8340 \\
\hline \multirow[t]{2}{*}{ Type IV } & $06: 56$ & - & $11: 29$ & IV & - & - & $698 x-110 x$ & - & - & - & Pulsations \\
\hline & & & & & & & & & & & NOAA 8340 \\
\hline CME & LASCO & DATA & GAP & & & & & & & & - \\
\hline SXR & $06: 40$ & $07: 13$ & 07:31 & M7.1 & $1.2 \times 10^{-1}$ & - & - & - & - & & NOAA 8340 \\
\hline $\mathrm{H} \alpha(\mathrm{SVI})$ & $06: 44$ & 07:06 & 10:09 & $3 \mathrm{~B}$ & - & N18E09 & - & - & - & - & NOAA 8340 \\
\hline Event 15: & 30 Sep. & 1998 & & & & & & & & & \\
\hline \multirow[t]{4}{*}{ Type IV } & $13: 11$ & - & $14: 50$ & IV & - & - & $500-110 x$ & - & - & - & Pulsations \\
\hline & & & & & & & & & & & NOAA 8340 \\
\hline & & & & & & & & & & & or \\
\hline & & & & & & & & & & & NOAA 8345 \\
\hline Type II & $13: 22$ & - & $13: 30$ & II & - & - & $40 x-90 x$ & - & - & - & From AIP \\
\hline CME & LASCO & DATA & GAP & & & & & & & & - \\
\hline $\mathrm{H} \alpha$ (RAMY) & $13: 24$ & $13: 34$ & $13: 39$ & SF & - & N21W71 & - & - & - & - & NOAA 8345 \\
\hline $\mathrm{H} \alpha$ (RAMY) & $13: 14$ & $13: 31$ & $13: 39$ & SF & - & N19W85 & - & - & - & - & NOAA 8340 \\
\hline Event 16: & 25 Oct. & 1998 & & & & & & & & & \\
\hline \multirow[t]{2}{*}{ Type II } & $13: 55$ & - & $13: 58$ & II & - & - & $110-450$ & 0.006 & 1270 & - & Harmonic \\
\hline & $13: 54$ & & & & & & & & & & \\
\hline SXR & $13: 51$ & $13: 56$ & $14: 04$ & $\mathrm{C} 2.2$ & $1.2 \times 10^{-3}$ & - & - & - & - & - & NOAA 8366 \\
\hline $\mathrm{H} \alpha$ (RAMY) & $13: 54$ & //// & $14: 15$ & SN & - & S11W53 & - & - & - & - & NOAA 8366 \\
\hline Event 17: & 02 Nov. & 1998 & & & & & & & & & \\
\hline Type IV & $13: 48$ & - & $14: 22$ & IV & - & - & $500-110$ & - & - & - & NOAA 9811 \\
\hline Type II & $13: 59$ & - & $14: 08$ & II & - & - & $40-130$ & - & - & - & From AIP \\
\hline \multirow[t]{2}{*}{ CME } & $13: 26$ & - & - & - & - & 116 & - & - & 661 & 0.0 & - \\
\hline & $14: 18$ & & & & & 169 & & & & & \\
\hline SXR & $13: 55$ & $14: 09$ & $14: 33$ & $\mathrm{C} 4.4$ & $8.5 \times 10^{-3}$ & - & - & - & - & - & - \\
\hline $\mathrm{H} \alpha(\mathrm{HOL})$ & $14: 02$ & $14: 06$ & $16: 04$ & $1 \mathrm{~N}$ & - & $\mathrm{S} 25 \mathrm{E} 44$ & - & - & - & - & NOAA 9811 \\
\hline \multirow[t]{3}{*}{ No Data } & Jan. & to & MAY & 1999 & & & & & & & Due to \\
\hline & & & & & & & & & & & technical \\
\hline & & & & & & & & & & & problems \\
\hline
\end{tabular}


C. Caroubalos et al.: ARTEMIS-IV type II/IV observations during 1998-2000, Online Material p 7

Table A.1. continued.

\begin{tabular}{|c|c|c|c|c|c|c|c|c|c|c|c|}
\hline \multirow[t]{3}{*}{ Observation } & Start & Peak & End & Class & Integ & Location & Freq & Drift & Vel & Accel & \multirow[t]{3}{*}{ Remarks } \\
\hline & \multirow[t]{2}{*}{ UT } & \multirow[t]{2}{*}{ UT } & \multirow[t]{2}{*}{ UT } & & \multirow{2}{*}{\multicolumn{2}{|c|}{$\begin{array}{l}\text { Flux } \\
\mathrm{J} / \mathrm{m}^{2}\end{array}$}} & Range & $\frac{1}{f} \frac{\mathrm{d} f}{\mathrm{~d} t}$ & \multirow[t]{2}{*}{$\mathrm{km} \mathrm{s}^{-1}$} & \multirow[t]{2}{*}{$\mathrm{m} / \mathrm{s}^{2}$} & \\
\hline & & & & & & & $\mathrm{MHz}$ & $\mathrm{s}^{-1}$ & & & \\
\hline Event 18: & 30 June & 1999 & & & & & & & & & \\
\hline \multirow[t]{4}{*}{ Type IV } & $11: 26$ & - & $11: 38$ & IV & - & - & $110 x-450$ & - & - & - & Pulsations \\
\hline & & & & & & & & & & & and some \\
\hline & & & & & & & & & & & Fibers \\
\hline & & & & & & & & & & & NOAA 8603 \\
\hline \multirow[t]{2}{*}{ Type II } & $11: 30$ & - & $11: 32$ & II & - & - & $40-75$ & - & - & - & Harmonic \\
\hline & & & & & & & & & & & From AIP \\
\hline Ass. Bursts & $11: 25: 30$ & - & $11: 28$ & III & - & - & $698-110 x$ & - & - & - & GG \\
\hline \multirow[t]{2}{*}{ CME } & 11:00 & - & - & - & - & Halo & - & - & 406 & -9.5 & - \\
\hline & $11: 54$ & & & & & - & & & & & \\
\hline SXR & $11: 24$ & $11: 30$ & $11: 38$ & M1.9 & $1.1 \times 10^{-2}$ & - & - & - & - & - & NOAA 8603 \\
\hline $\mathrm{H} \alpha(\mathrm{SVI})$ & $11: 23$ & $11: 33$ & $11: 56$ & $1 \mathrm{~B}$ & - & S15E00 & - & - & - & - & NOAA 8603 \\
\hline Event 19: & 11 July & 1999 & & & & & & & & & \\
\hline \multirow[t]{2}{*}{ Type II } & $13: 23$ & - & $13: 26$ & II & - & - & $220-110$ & 0.004 & 1213 & - & Harmonic \\
\hline & $13: 18$ & & & & & & & & & & \\
\hline Ass. Bursts & $13: 12$ & - & $13: 26$ & III & - & - & $300-110$ & - & - & - & GG \\
\hline \multirow[t]{2}{*}{ CME } & $12: 24$ & - & - & - & - & 236 & - & - & 389 & -25.5 & - \\
\hline & $13: 54$ & & & & & 085 & & & & & \\
\hline SXR & $13: 14$ & $13: 19$ & $13: 25$ & $\mathrm{C} 2.2$ & $1.2 \times 10^{-3}$ & - & - & - & - & & NOAA 8626 \\
\hline $\mathrm{H} \alpha$ (RAMY) & $13: 10$ & $13: 19$ & $13: 30$ & SF & - & S20W51 & - & - & - & - & NOAA 8626 \\
\hline Event 20: & 13 July & 1999 & & & & & & & & & \\
\hline Type IV & $05: 57$ & - & 05:59 & IV & - & - & $250-600$ & - & - & - & Pulsations \\
\hline \multirow[t]{2}{*}{ Type II } & 06:02:30 & - & 06:05 & II & - & - & $160-110$ & 0.0023 & 706 & - & Harmonic \\
\hline & $05: 51$ & & & & & & & & & & \\
\hline Ass. Bursts & $05: 57$ & - & 05:59 & III & - & - & $350-140$ & - & - & - & GG, U \\
\hline SXR & $05: 22$ & $05: 46$ & 06:09 & $\mathrm{C} 2.9$ & $5.4 \times 10^{-3}$ & - & - & - & - & & - \\
\hline $\mathrm{H} \alpha$ (LEAR) & $05: 59$ & 06:00 & 06:08 & SF & - & N16E06 & - & - & - & - & NOAA 8628 \\
\hline
\end{tabular}


C. Caroubalos et al.: ARTEMIS-IV type II/IV observations during 1998-2000, Online Material p 8

Table A.1. continued.

\begin{tabular}{llllllllllll}
\hline \hline Observation & Start & Peak & End & Class & Integ & Location & Freq & Drift & Vel & Accel Remarks \\
& UT & UT & UT & & Flux & & Range & $\frac{1}{f} \frac{\mathrm{d} f}{\mathrm{~d} t}$ & $\mathrm{~km} \mathrm{~s}^{-1}$ & $\mathrm{~m} / \mathrm{s}^{2}$ & \\
& & & & & $\mathrm{~J} / \mathrm{m}^{2}$ & & $\mathrm{MHz}$ & $\mathrm{s}^{-1}$ & & & \\
& & & & & & & & & &
\end{tabular}

\begin{tabular}{|c|c|c|c|c|c|c|c|c|c|c|c|}
\hline Event 21: & 21 July & 1999 & & & & & & & & & \\
\hline \multirow[t]{2}{*}{ Type II } & 09:13 & - & 09:16 & II & - & - & $200-110$ & 0.0014 & 430 & - & Harmonic \\
\hline & $08: 57$ & & & & & & & & & & \\
\hline Ass. Bursts & 09:10 & - & 09:12 & III & - & - & $400-110$ & - & - & - & GG \\
\hline \multirow[t]{2}{*}{ CME } & 09:00 & - & - & - & - & 133 & - & - & 451 & -69.5 & - \\
\hline & $10: 31$ & & & & & 012 & & & & & - \\
\hline SXR & 09:09 & $09: 13$ & 09:16 & B7.4 & $2.6 \times 10^{-4}$ & - & - & - & - & & - \\
\hline
\end{tabular}

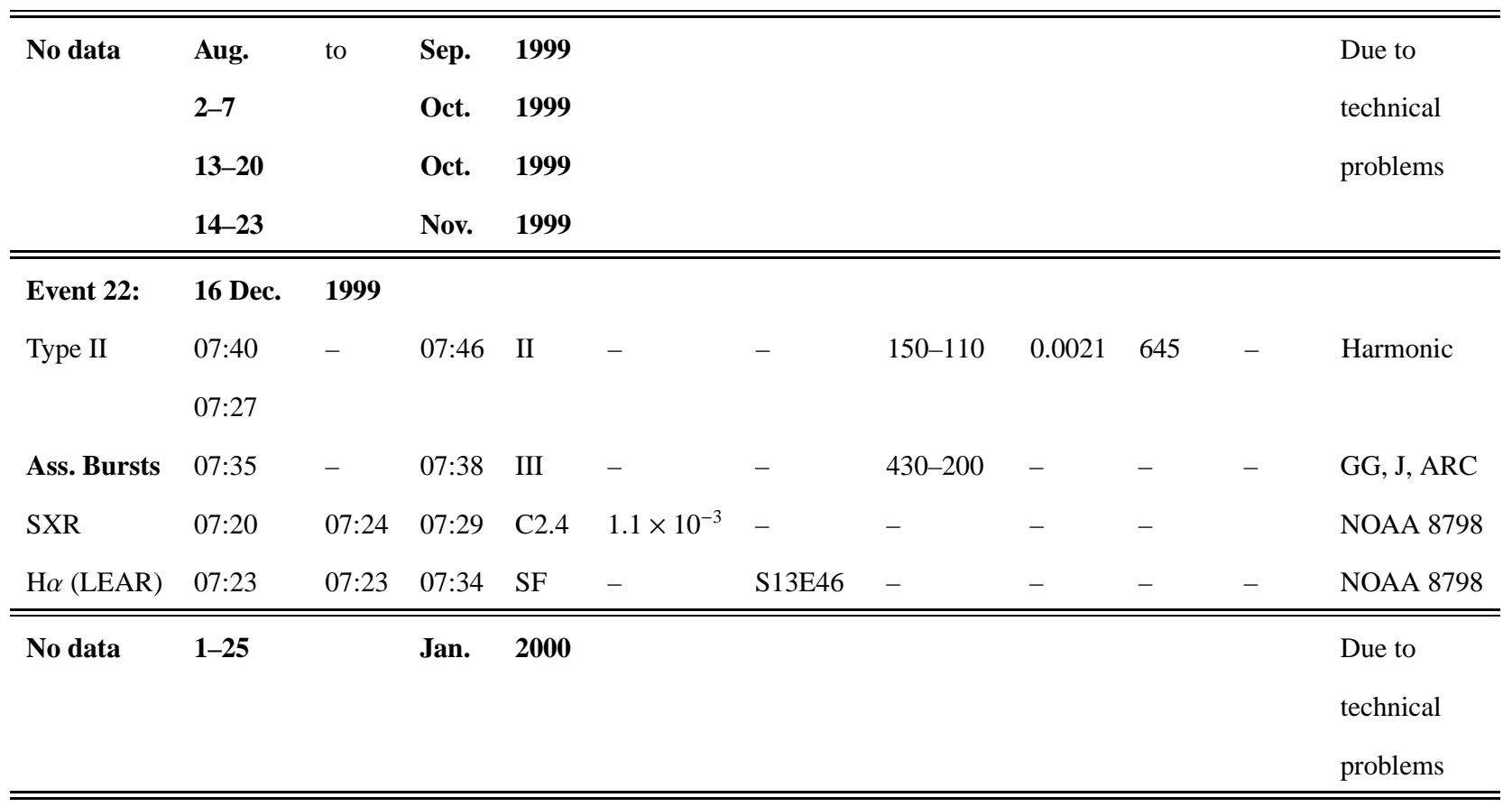

\begin{tabular}{|c|c|c|c|c|c|c|c|c|c|c|c|}
\hline Event 23: & 08 Feb. & 2000 & & & & & & & & & \\
\hline \multirow[t]{2}{*}{ Type IV } & $08: 55: 30$ & - & 09:04 & IV & - & - & $110-500$ & - & - & - & Pulsations \\
\hline & & & & & & & & & & & NOAA 8858 \\
\hline \multirow[t]{2}{*}{ Type II } & $08: 51$ & - & 09:02 & II & - & - & $200-110 x$ & 0.0012 & 806 & - & Harmonic \\
\hline & $08: 33$ & & & & & & & & & & NOAA 8858 \\
\hline Ass. Bursts & $08: 48$ & - & 08:53 & III & - & - & $440-110 x$ & - & - & - & GG \\
\hline \multirow[t]{2}{*}{ CME } & 08:51 & - & - & - & - & Halo & - & - & 1079 & -35.5 & \\
\hline & 09:30 & & & & & - & & & & & \\
\hline SXR & $08: 42$ & 09:00 & 09:18 & M1.3 & $1.8 \times 10^{-2}$ & - & - & - & - & & NOAA 8858 \\
\hline $\mathrm{H} \alpha$ (LEAR) & $08: 43$ & 08:56 & 09:59 & 1B & - & N25E26 & - & - & - & - & NOAA 8858 \\
\hline
\end{tabular}




\section{Caroubalos et al.: ARTEMIS-IV type II/IV observations during 1998-2000, Online Material p 9}

Table A.1. continued.

\begin{tabular}{|c|c|c|c|c|c|c|c|c|c|c|c|}
\hline \multirow[t]{3}{*}{ Observation } & Start & Peak & End & Class & Integ & Location & Freq & Drift & Vel & Accel & Remarks \\
\hline & \multirow[t]{2}{*}{ UT } & \multirow[t]{2}{*}{ UT } & \multirow[t]{2}{*}{ UT } & & \multirow{2}{*}{\multicolumn{2}{|c|}{$\begin{array}{l}\text { Flux } \\
\mathrm{J} / \mathrm{m}^{2}\end{array}$}} & Range & $\frac{1}{f} \frac{\mathrm{d} f}{\mathrm{~d} t}$ & \multirow[t]{2}{*}{$\mathrm{km} \mathrm{s}^{-1}$} & \multirow[t]{2}{*}{$\mathrm{m} / \mathrm{s}^{2}$} & \\
\hline & & & & & & & $\mathrm{MHz}$ & $\mathrm{s}^{-1}$ & & & \\
\hline Event 24: & 02 Mar. & 2000 & & & & & & & & & \\
\hline \multirow[t]{2}{*}{ Type II } & $08: 27$ & - & 08:30 & II & - & - & $300-110$ & 0.0092 & 1940 & - & Harmonic \\
\hline & $08: 25$ & & & & & & & & & & NOAA 8882 \\
\hline Ass. Bursts & 08:22 & - & 08:25 & III & - & - & $400-110$ & - & - & - & GG \\
\hline \multirow[t]{2}{*}{ CME } & $07: 52$ & - & - & - & - & 231 & - & - & 776 & 1.0 & \\
\hline & 08:54 & & & & & 062 & & & & & \\
\hline SXR & $08: 20$ & $08: 28$ & $08: 31$ & X1.1 & $3.6 \times 10^{-2}$ & - & - & - & - & & NOAA 8882 \\
\hline $\mathrm{H} \alpha$ (LEAR) & $08: 23$ & $08: 25$ & 09:11 & $2 \mathrm{~B}$ & - & S14W52 & - & - & - & - & NOAA 8882 \\
\hline Event 25: & 02 Mar. & 2000 & & & & & & & & & \\
\hline \multirow[t]{2}{*}{ Type IV } & $13: 40: 45$ & - & $13: 44$ & IV & - & - & $130-600$ & - & - & - & Pulsations \\
\hline & & & & & & & & & & & NOAA 8882 \\
\hline \multirow[t]{2}{*}{ Type II } & $13: 41$ & - & $13: 42$ & II & - & - & $300-110$ & 0.007 & 1477 & - & Harmonic \\
\hline & $13: 39$ & & & & & & & & & & NOAA 8882 \\
\hline Ass. Bursts & $13: 38$ & - & $13: 42$ & III & - & - & $600-110 x$ & - & - & - & GG \\
\hline \multirow[t]{2}{*}{ CME } & $12: 51$ & - & - & - & - & 235 & - & - & 835 & -1.0 & \\
\hline & $13: 54$ & & & & & 076 & & & & & \\
\hline SXR & 13:06 & $13: 15$ & $13: 26$ & C5.5 & $4.7 \times 10^{-3}$ & - & - & - & - & & NOAA 8882 \\
\hline SXR & $13: 35$ & $13: 43$ & $13: 48$ & M6.5 & $2.9 \times 10^{-3}$ & - & - & - & - & & NOAA 8882 \\
\hline H $\alpha$ (RAMY) & 13:08 & 13:08 & $13: 26$ & $\mathrm{SF}$ & - & S19W60 & - & - & - & - & NOAA 8882 \\
\hline $\mathrm{H} \alpha(\mathrm{RAMY})$ & $13: 40$ & $13: 41$ & $13: 56$ & SN & - & S20W58 & - & - & - & - & NOAA 8882 \\
\hline Event 26: & 07 Mar. & 2000 & & & & & & & & & \\
\hline Type IV & $14: 26$ & - & $14: 55$ & IV & - & - & $115-400$ & - & - & - & Pulsations \\
\hline \multirow[t]{2}{*}{ Type II } & $14: 26$ & - & $14: 27: 30$ & II & - & - & $300-110 x$ & 0.007 & 1820 & - & Harmonic \\
\hline & $14: 24$ & & & & & & & & & & NOAA 8891 \\
\hline SXR & $14: 21$ & $14: 30$ & $14: 36$ & C6.3 & $4.3 \times 10^{-3}$ & - & - & - & - & & NOAA 8891 \\
\hline $\mathrm{H} \alpha(\mathrm{SVI})$ & $14: 23$ & $14: 36$ & $14: 42$ & SF & - & S13W59 & - & - & - & - & NOAA 8891 \\
\hline Event 27: & 19 Mar. & 2000 & & & & & & & & & \\
\hline \multirow[t]{2}{*}{ Type II } & $11: 46$ & - & $11: 47$ & II & - & - & $170-120$ & 0.0012 & 375 & - & Harmonic \\
\hline & $11: 25$ & & & & & & & & & - & \\
\hline \multirow[t]{2}{*}{ CME } & $11: 12$ & - & - & - & - & 235 & - & - & 350 & 5 & \\
\hline & $12: 30$ & & & & & 077 & & & & & \\
\hline SXR & $11: 03$ & 11:07 & $11: 15$ & $\mathrm{C} 2.2$ & $1.4 \times 10^{-3}$ & - & - & - & - & & NOAA 8906 \\
\hline $\mathrm{H} \alpha$ (RAMY) & 11:05 & 11:06 & $11: 10$ & $\mathrm{SF}$ & - & S20W69 & - & - & - & - & NOAA 8906 \\
\hline
\end{tabular}


Table A.1. continued.

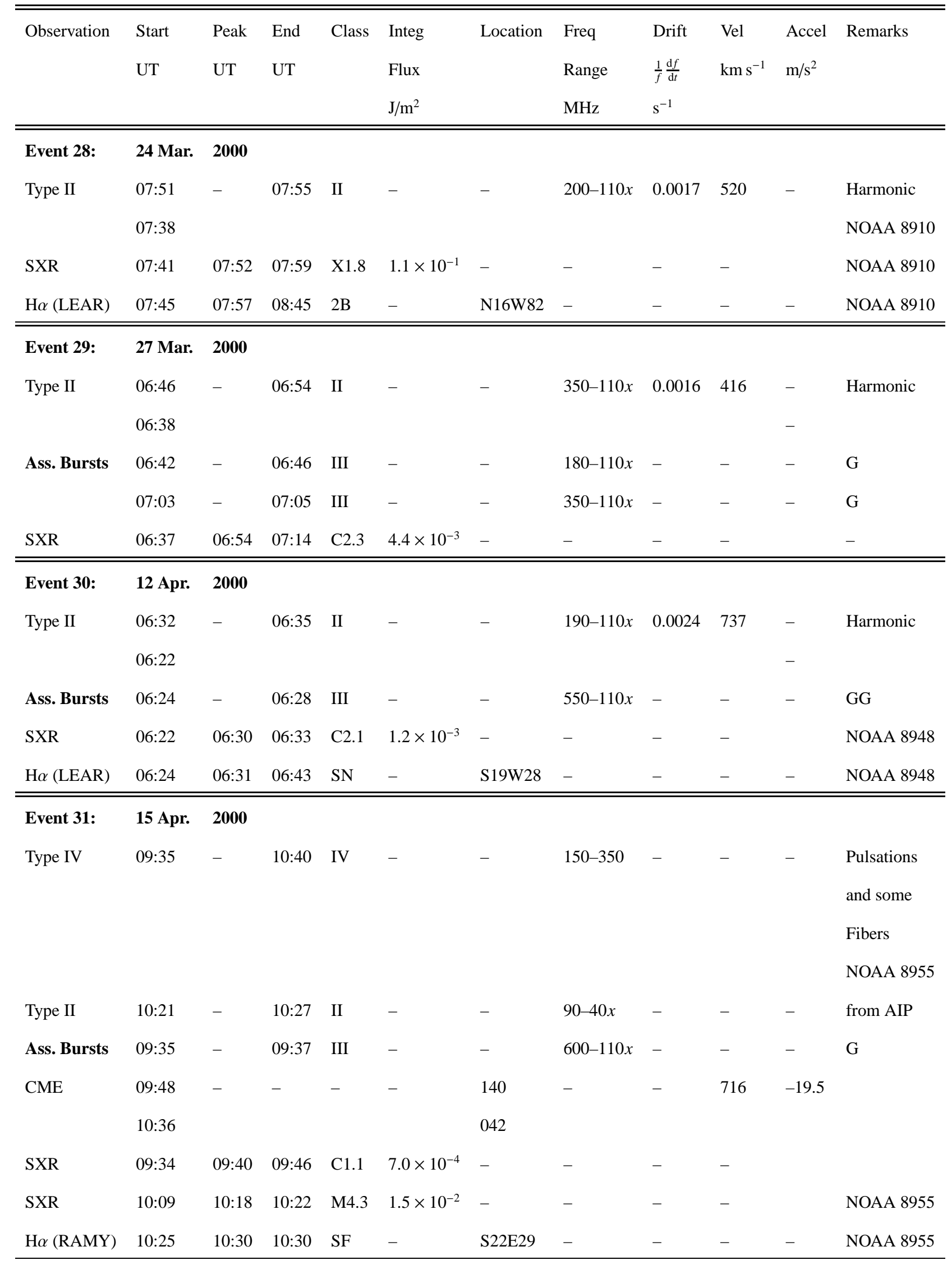


C. Caroubalos et al.: ARTEMIS-IV type II/IV observations during 1998-2000, Online Material p 11

Table A.1. continued.

\begin{tabular}{|c|c|c|c|c|c|c|c|c|c|c|c|}
\hline \multirow[t]{2}{*}{ Observation } & \multirow[t]{2}{*}{ UT } & \multirow[t]{2}{*}{ UT } & \multirow[t]{2}{*}{ UT } & Class & \multirow{2}{*}{\multicolumn{2}{|c|}{$\begin{array}{l}\text { Flux } \\
\mathrm{J} / \mathrm{m}^{2}\end{array}$}} & $\begin{array}{l}\text { Freq } \\
\text { Range }\end{array}$ & $\begin{array}{l}\text { Drift } \\
\frac{1}{f} \frac{\mathrm{d} f}{\mathrm{~d} t}\end{array}$ & \multirow[t]{2}{*}{$\mathrm{km} \mathrm{s}^{-1}$} & \multirow[t]{2}{*}{$\mathrm{m} / \mathrm{s}^{2}$} & Remarks \\
\hline & & & & & & & $\mathrm{MHz}$ & $\mathrm{s}^{-1}$ & & & \\
\hline Event 32: & 30 Apr. & 2000 & & & & & & & & & \\
\hline Type IV & $07: 59$ & - & $08: 30$ & IV & - & - & $200-698$ & - & - & - & Pulsations \\
\hline \multirow[t]{2}{*}{ Type II } & $07: 58$ & - & 08:02 & II & - & - & $110-258$ & 0.00144 & 442 & - & Harmonic \\
\hline & $07: 46$ & & & & & & & & & & \\
\hline Ass. Bursts & $07: 55$ & - & $07: 57$ & III & - & - & $270-110 x$ & - & - & - & $\mathrm{G}$ \\
\hline \multirow[t]{2}{*}{ CME } & $07: 49$ & - & - & - & - & 186 & - & - & 540 & 7.5 & \\
\hline & $08: 54$ & & & & & 104 & & & & & \\
\hline SXR & 07:53 & 08:08 & 08:31 & C7.7 & $1.2 \times 10^{-2}$ & - & - & - & - & & NOAA 8976 \\
\hline $\mathrm{H} \alpha$ (LEAR) & $07: 55$ & 08:00 & $09: 16$ & $1 \mathrm{~N}$ & - & S11W18 & - & - & - & - & NOAA 8976 \\
\hline Event 33: & 02 May & 2000 & & & & & & & & & \\
\hline \multirow[t]{2}{*}{ Type II } & $14: 48$ & - & $14: 53$ & II & - & - & $350-125$ & 0.005 & 1300 & - & NOAA 8971 \\
\hline & $14: 45$ & & & & & & & & & & \\
\hline Ass. Bursts & $14: 44$ & - & $14: 48: 30$ & III & - & - & $500-110 x$ & - & - & - & GG \\
\hline \multirow[t]{2}{*}{ CME } & $14: 30$ & - & - & - & - & 293 & - & - & 1278 & -44.5 & \\
\hline & 15:06 & & & & & 040 & & & & & \\
\hline SXR & $14: 42$ & $14: 51$ & $14: 56$ & M2.8 & $1.4 \times 10^{-2}$ & - & - & - & - & & NOAA 8971 \\
\hline $\mathrm{H} \alpha(\mathrm{HOL})$ & $14: 45$ & $14: 46$ & $15: 05$ & $1 \mathrm{~N}$ & - & N22W68 & - & - & - & - & NOAA 8971 \\
\hline Event 34: & 07 Jul. & 2000 & & & & & & & & & \\
\hline \multirow[t]{2}{*}{ Type IV } & $11: 30$ & - & $11: 55$ & IV & - & - & $200-500$ & - & - & - & Pulsations \\
\hline & & & & & & & & & & & NOAA 9070 \\
\hline Type II & $11: 23$ & - & $13: 18$ & II & - & - & $70-20$ & - & - & - & Nançay \\
\hline SXR & 08:42 & 09:21 & $10: 11$ & C5.6 & $1.7 \times 10^{-2}$ & - & - & - & - & & NOAA 9070 \\
\hline $\mathrm{H} \alpha(\mathrm{SVI})$ & 09:08 & 09:18 & 09:59 & SF & - & N17E10 & - & - & - & - & NOAA 9070 \\
\hline Event 35: & 11 Jul. & 2000 & & & & & & & & & \\
\hline \multirow[t]{2}{*}{ Type IV } & $12: 36$ & - & $15: 20$ & IV & - & - & $110-698$ & - & - & - & Pulsations \\
\hline & & & & & & & & & & & NOAA 9077 \\
\hline Type II & $12: 46$ & - & $13: 53$ & II & - & - & $70-20$ & - & - & - & Nançay \\
\hline \multirow[t]{2}{*}{ CME } & $13: 27$ & - & - & - & - & Halo & - & - & 1078 & -43.0 & \\
\hline & $13: 27: 20$ & & & & & - & & & & & \\
\hline SXR & $12: 12$ & $13: 10$ & $13: 35$ & $\mathrm{X} 1.0$ & $3.1 \times 10^{-1}$ & - & - & - & - & & NOAA 9077 \\
\hline $\mathrm{H} \alpha(\mathrm{HOL})$ & $13: 20$ & $13: 23$ & $18: 37$ & $2 \mathrm{~N}$ & - & N18E27 & - & - & - & - & NOAA 9077 \\
\hline
\end{tabular}


Table A.1. continued.

\begin{tabular}{lllllllllll}
\hline \hline Observation & Start & Peak & End & Class & Integ & Location & Freq & Drift & Vel & Accel Remarks \\
& UT & UT & UT & & Flux & & Range & $\frac{1}{f} \frac{\mathrm{d} f}{\mathrm{~d} t}$ & $\mathrm{~km} \mathrm{~s}^{-1}$ & $\mathrm{~m} / \mathrm{s}^{2}$ \\
\\
\end{tabular}

\begin{tabular}{|c|c|c|c|c|c|c|c|c|c|c|c|}
\hline Event 36: & 14 Jul. & 2000 & & & & & & & & & \\
\hline \multirow[t]{2}{*}{ Type II } & 10:09 & - & $10: 26$ & II & - & - & $300-110$ & 0.0055 & 1430 & - & Harmonic \\
\hline & 10:06 & & & & & & & & & & \multirow[t]{3}{*}{ NOAA 9077} \\
\hline Type IV & $10: 27$ & - & $10: 41$ & IV & - & - & $150-698$ & - & - & - & \\
\hline (phase 1) & & & & & & & & & & & \\
\hline \multirow[t]{3}{*}{ (phase 2) } & $10: 38$ & - & $11: 26$ & IV & - & - & $150-698$ & - & - & - & Pulsations \\
\hline & & & & & & & & & & & Fibers \\
\hline & & & & & & & & & & & NOAA 9077 \\
\hline Ass. Bursts & 10:00 & - & $10: 31$ & III & - & - & $440-110 x$ & - & - & - & \multirow[t]{3}{*}{ GG } \\
\hline \multirow[t]{2}{*}{ CME } & $10: 18$ & - & - & - & - & Halo & - & - & 1674 & -96.0 & \\
\hline & $10: 54$ & & & & & - & & & & & \\
\hline SXR & 10:03 & $10: 24$ & $10: 43$ & $\mathrm{X} 57$ & $7.5 \times 10^{-1}$ & - & - & - & - & & NOAA 9077 \\
\hline $\mathrm{H} \alpha$ (RAMY) & $10: 53$ & 11:02 & $13: 30$ & $2 \mathrm{~B}$ & - & N17E01 & - & - & - & - & NOAA 9077 \\
\hline
\end{tabular}

Event 37: $\quad 14$ Jul. 2000

$\begin{array}{lllllllllllll}\text { Type IV } & 12: 49 & - & 13: 15 & \text { IV } & - & & & - & 110-698 & - & & \end{array}$

(phase 1)

$\begin{array}{lllllllllllll}\text { (phase 2) } & 13: 48 & - & 13: 57 & \text { IV } & - & & - & 130-320 & - & & & \end{array}$

NOAA 9085

\begin{tabular}{llllllllllll} 
Ass. Bursts & $13: 48$ & - & $13: 51$ & III & - & - & $440-110 x$ & - & - & - & G \\
H $\alpha$ (RAMY) & $13: 00$ & $13: 00$ & $13: 37$ & SF & - & N12E50 & - & - & - & - & NOAA 9085 \\
\hline \hline Event 38: & $\mathbf{1 5}$ Jul. & $\mathbf{2 0 0 0}$ & & & & & & & & & \\
Type II & $14: 32$ & - & $14: 38$ & II & - & - & $200-110$ & 0.0021 & 652 & - & F-H \\
& $14: 21$ & & & & & & & & & & \\
Ass. Bursts & $14: 32$ & - & $14: 36$ & III & - & - & $250-110 x$ & - & - & - & GG \\
H $\alpha$ (RAMY) & $14: 32$ & $14: 37$ & $14: 44$ & SF & - & S09W18 & - & - & - & - & NOAA 9082 \\
\hline
\end{tabular}


Table A.1. continued.

\begin{tabular}{|c|c|c|c|c|c|c|c|c|c|c|c|}
\hline Observation & $\begin{array}{l}\text { Start } \\
\text { UT }\end{array}$ & $\begin{array}{l}\text { Peak } \\
\text { UT }\end{array}$ & $\begin{array}{l}\text { End } \\
\text { UT }\end{array}$ & Class & $\begin{array}{l}\text { Integ } \\
\text { Flux } \\
\mathrm{J} / \mathrm{m}^{2}\end{array}$ & Location & $\begin{array}{l}\text { Freq } \\
\text { Range } \\
\mathrm{MHz}\end{array}$ & $\begin{array}{l}\text { Drift } \\
\frac{1}{f} \frac{\mathrm{d} f}{\mathrm{~d} t} \\
\mathrm{~s}^{-1}\end{array}$ & $\begin{array}{l}\text { Vel } \\
\mathrm{km} \mathrm{s}^{-1}\end{array}$ & $\begin{array}{l}\text { Accel } \\
\mathrm{m} / \mathrm{s}^{2}\end{array}$ & Remarks \\
\hline Event 39: & 19 Sep. & 2000 & & & & & & & & & \\
\hline Type II & $\begin{array}{l}08: 14 \\
08: 05\end{array}$ & - & $08: 21$ & II & - & - & $270-115$ & 0.0019 & 494 & - & $\begin{array}{l}\text { Harmonic } \\
\text { NOAA } 9165\end{array}$ \\
\hline Type IV & $08: 15$ & - & 08:40 & IV & - & - & $150-698$ & - & - & - & $\begin{array}{l}\text { Pulsations } \\
\text { NOAA } 9165\end{array}$ \\
\hline Ass. Bursts & 08:12 & - & 08:14 & III & - & - & $400-150$ & - & - & - & $\mathrm{G}, \mathrm{U}$ \\
\hline CME & $\begin{array}{l}07: 53 \\
08: 50\end{array}$ & - & - & - & - & $\begin{array}{l}283 \\
076\end{array}$ & - & - & 766 & 10.5 & \\
\hline SXR & 08:06 & $08: 26$ & $08: 42$ & M5.1 & $7.1 \times 10^{-2}$ & - & - & - & - & & NOAA 9165 \\
\hline $\mathrm{H} \alpha$ (LEAR) & 08:09 & 08:12 & 09:30 & $1 \mathrm{~N}$ & $\underline{-}$ & N14W46 & - & - & - & - & NOAA 9165 \\
\hline Event 40: & 18 Nov. & 2000 & & & & & & & & & \\
\hline Type II & $\begin{array}{l}13: 11 \\
13: 04\end{array}$ & - & $13: 14$ & II & - & - & $300-110$ & 0.0023 & 598 & - & $\begin{array}{l}\text { Harmonic } \\
\text { NOAA } 9235\end{array}$ \\
\hline Type IV & 13:08 & - & $13: 42$ & IV & - & - & $110 \times-698$ & - & - & - & $\begin{array}{l}\text { Pulsations } \\
\text { NOAA } 9235\end{array}$ \\
\hline CME & $\begin{array}{l}13: 21: 36 \\
13: 54\end{array}$ & - & - & - & - & $\begin{array}{l}074 \\
120\end{array}$ & - & - & 553 & 16 & \\
\hline SXR & $13: 02$ & $13: 25$ & $13: 50$ & M1.5 & $3.1 \times 10^{-2}$ & - & - & - & - & & NOAA 9235 \\
\hline $\mathrm{H} \alpha$ (RAMY) & 13:06 & $13: 15$ & $14: 19$ & $1 \mathrm{~F}$ & - & N11E37 & - & - & - & - & NOAA 9235 \\
\hline
\end{tabular}

